\title{
ABA crosstalk with ethylene and nitric oxide in seed dormancy and germination
}

\author{
Erwann Arc ${ }^{1,2}$, Julien Sechet ${ }^{1}$, Françoise Corbineau ${ }^{3}$, Loïc Rajjou ${ }^{1,2}$ and Annie Marion-Poll ${ }^{\text {* }}$ \\ I Institut Jean-Pierre Bourgin (UMR1318 INRA - AgroParisTech), Institut National de la Recherche Agronomique, Saclay Plant Science, Versailles, France \\ 2 UFR de Physiologie végétale, AgroParisTech, Paris, France \\ ${ }^{3}$ Germination et Dormance des Semences, UR5 UPMC-EAC 7180 CNRS, Université Pierre et Marie Curie-Paris 6, Paris, France
}

\section{Edited by:}

Sergi Munné-Bosch, University of

Barcelona, Spain

Reviewed by:

Inhwan Hwang, Pohang University of Science and Technology, South Korea Dawei Yan, University of Toronto,

\section{Canada}

\section{${ }^{*}$ Correspondence:}

Annie Marion-Poll, Institut Jean-Pierre Bourgin (UMR1318 INRA -

AgroParisTech), Institut National de la Recherche Agronomique, Saclay Plant Science, Route de Saint Cyr, F-78026 Versailles Cedex, France.

e-mail: annie.marion-poll@versailles. inra.fr

\begin{abstract}
Dormancy is an adaptive trait that enables seed germination to coincide with favorable environmental conditions. It has been clearly demonstrated that dormancy is induced by abscisic acid (ABA) during seed development on the mother plant. After seed dispersal, germination is preceded by a decline in $A B A$ in imbibed seeds, which results from $A B A$ catabolism through 8'-hydroxylation. The hormonal balance between ABA and gibberellins (GAs) has been shown to act as an integrator of environmental cues to maintain dormancy or activate germination. The interplay of ABA with other endogenous signals is however less documented. In numerous species, ethylene counteracts ABA signaling pathways and induces germination. In Brassicaceae seeds, ethylene prevents the inhibitory effects of $A B A$ on endosperm cap weakening, thereby facilitating endosperm rupture and radicle emergence. Moreover, enhanced seed dormancy in Arabidopsis ethylene-insensitive mutants results from greater ABA sensitivity. Conversely, ABA limits ethylene action by down-regulating its biosynthesis. Nitric oxide (NO) has been proposed as a common actor in the ABA and ethylene crosstalk in seed. Indeed, convergent evidence indicates that $\mathrm{NO}$ is produced rapidly after seed imbibition and promotes germination by inducing the expression of the ABA 8'-hydroxylase gene, CYP707A2, and stimulating ethylene production. The role of $\mathrm{NO}$ and other nitrogen-containing compounds, such as nitrate, in seed dormancy breakage and germination stimulation has been reported in several species. This review will describe our current knowledge of ABA crosstalk with ethylene and NO, both volatile compounds that have been shown to counteract ABA action in seeds and to improve dormancy release and germination.
\end{abstract}

Keywords: abscisic acid, dormancy, ethylene, germination, hormone, nitric oxide, seed

\section{INTRODUCTION}

Survival of plant species mainly relies on the sexual reproduction to give birth to new individuals. In flowering plants, the seed is the main unit of dispersal and allows colonization of new geographic areas. As a consequence of the double fertilization process, a mature angiosperm seed contains a diploid embryo and protective layers comprising the triploid endosperm, a nourishing tissue for the embryo, and the seed coat of maternal origin. During development on the mother plant, after embryogenesis completion, reserve accumulation takes place and is followed, in so-called orthodox seeds, by an intense dehydration leading to low seed water content upon dispersal. In many species, a dormant state is also induced during the maturation phase, preventing pre-harvest germination and allowing seed survival until environmental conditions become suitable for germination and seedling establishment (Bentsink and Koornneef, 2008; Finkelstein et al., 2008; North et al., 2010).

Dormancy has been defined as a developmental state in which a viable seed fails to germinate under favorable environmental conditions (Bewley, 1997), but different definitions and classifications have been proposed. Finch-Savage and Leubner-Metzger (2006) summarized a classification proposed by Baskin and Baskin
(2004), based on the fact that dormancy results from physiological and developmental (or morphological) properties of the seed. Dormancy is therefore divided in five classes: (1) physiological dormancy (PD) can be released by different stratification (moist chilling) treatments depending on its depth, (2) morphological dormancy (MD) is due to a delay of embryo development, (3) morphophysiological dormancy (MPD) is combining both PD and MD, (4) physical dormancy (PY) is correlated with seed coat impermeability to water and needs disruption of the seed coat (scarification) to be released, and finally (5) combinational dormancy combining PY and PD. Most species display a non-deep PD corresponding to a dormancy that can be released, depending on the species, by gibberellin (GA) treatment, stratification, scarification, or a period of dry storage (after-ripening). In this case, seeds generally combine a coat-imposed dormancy due to the covering layers of the seed (seed coat and endosperm) that prevent the radicle protrusion, and an embryo dormancy due to its incapacity to induce radicle growth.

When dormancy is released, seeds can germinate under favorable conditions, specific to each species. The germination process, that begins with seed imbibition and finishes with a developed plantlet, is divided in three distinct phases of water uptake. Phase 
I starts with a fast water uptake and the activation of respiratory metabolism and transcriptional and translational activities. During phase II water uptake ceases, seed reserve mobilization begins and testa rupture occurs. Later, in the third phase water uptake resumes and endosperm rupture allows radicle protrusion; then starts the post-germination phase with high water uptake, mobilization of the major part of reserves and first cell divisions, until the complete seedling development (Bewley, 1997; Nonogaki et al., 2010; Weitbrecht et al., 2011). Germination sensu stricto ends with radicle protrusion. It is often described has the resulting consequence of the growth potential of the embryo and the resistance of the surrounding layers. Endosperm weakening is an essential part of the modification of seed envelopes for the progress of germination and involves the activation of cell-wall modifying enzymes (Finch-Savage and Leubner-Metzger, 2006; Endo et al., 2012; Linkies and Leubner-Metzger, 2012). After dormancy release, storage/imbibition of non-dormant seeds in unfavorable conditions for germination can trigger a secondary dormancy. This is a way to protect seeds against germination too late in the year and induce a seasonal cycling of dormancy level in seeds (Cadman et al., 2006; Footitt et al., 2011).

The regulation of seed dormancy and germination by the hormonal balance between abscisic acid (ABA) and GA, in response to environmental signals, is well documented in a number of recent reviews (Finkelstein et al., 2008; Seo et al., 2009; Nambara et al., 2010; Nonogaki et al., 2010; Weitbrecht et al., 2011; Graeber et al., 2012; Rajjou et al., 2012). The present review will describe recent knowledge about key players in the ABA metabolism and signaling pathways that control dormancy induction and maintenance and convergent evidences supporting the role of two other signaling compounds, nitric oxide (NO) and ethylene, in dormancy breakage and germination, and their interactions with ABA metabolism and signaling pathways.

\section{ABA HOMEOSTASIS AND SIGNALING IN DORMANCY CONTROL \\ ABA SYNTHESIS}

Abscisic acid is formed by cleavage of $\mathrm{C}_{40}$ oxygenated carotenoids, also called xanthophylls, which are produced in plastids from $\mathrm{C}_{5}$ precursors (Ruiz-Sola and Rodríguez-Concepción, 2012). Key genes encoding enzymes of the ABA biosynthesis pathway have been identified through mutant selection for altered germination phenotypes, giving further evidence of the major role of $\mathrm{ABA}$ in the regulation of seed dormancy and germination (Figure 1). For instance, the first ABA-deficient mutant, identified in Arabidopsis thaliana, was isolated in a GA biosynthesis mutant gal suppressor screen, on its ability to germinate in the absence of GA. It was shown to be defective in zeaxanthin epoxidase (ZEP) activity, like a Nicotiana plumbaginifolia mutant selected later on its early germination phenotype (Koornneef et al., 1982; Marin et al., 1996). ZEP catalyzes the epoxidation of zeaxanthin into violaxanthin and is encoded, in Arabidopsis, by the ABA1 gene (Audran et al., 2001; Xiong et al., 2002). Violaxanthin is then converted into neoxanthin, by neoxanthin synthase (NSY), likely encoded by the Arabidopsis ABA4 gene (Dall'Osto et al., 2007; North et al., 2007). Despite impairment in $A B A 4$ function completely prevents neoxanthin synthesis, the aba4 mutant exhibits no obvious dormancy

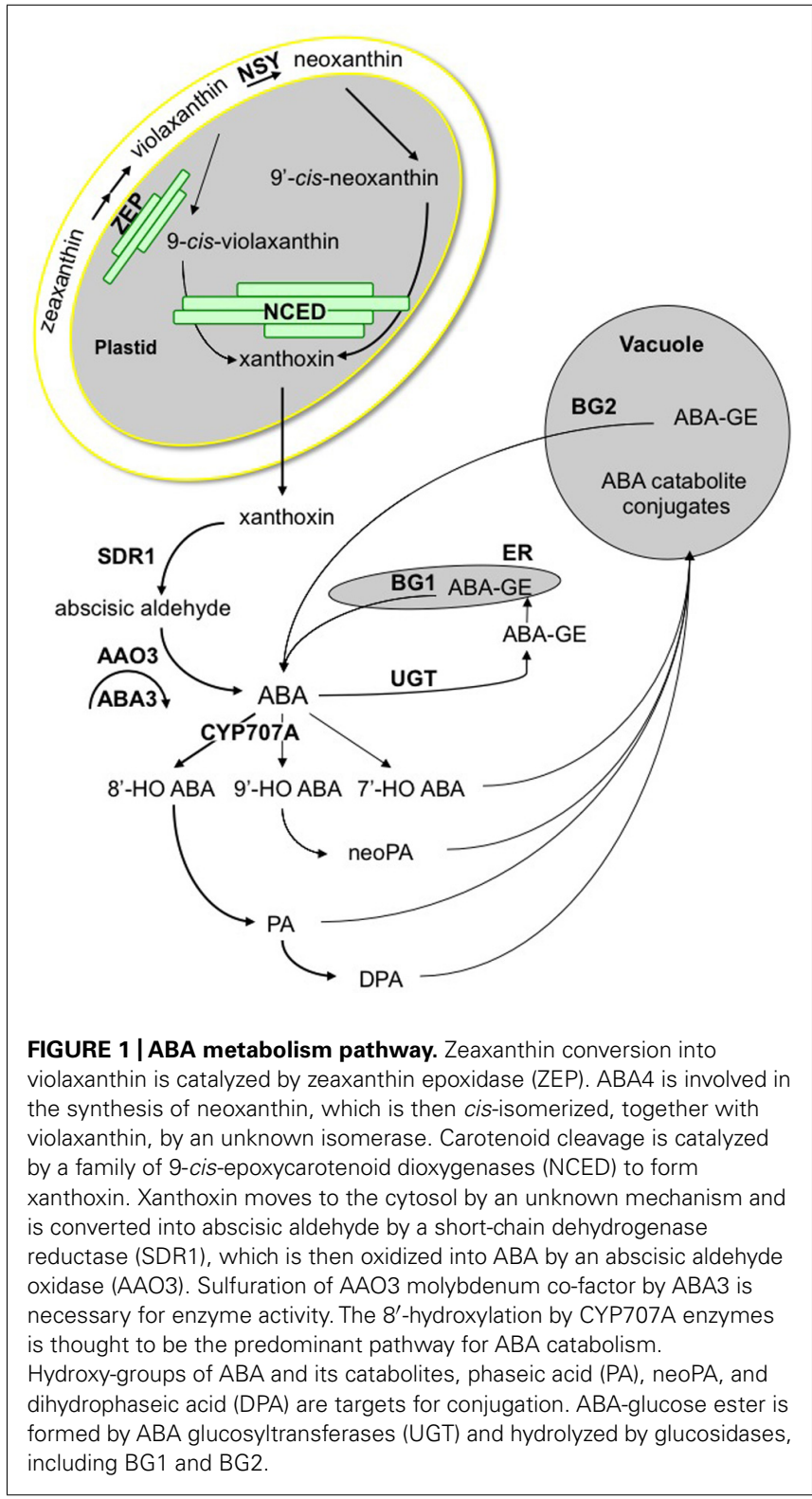

phenotype, due the formation of cis-violaxanthin by an alternate pathway (North etal., 2007). Both cis-violaxanthin and cisneoxanthin cleavage gives rise to xanthoxin, the $\mathrm{C}_{15}$ aldehyde precursor of ABA. Since cis-isomerization of violaxanthin and neoxanthin is required prior to cleavage, an unknown isomerase might be involved. The VIVIPAROUS14 (VP14) gene in maize (Zea mays) has been shown to encode a 9-cis-epoxycarotenoid dioxygenase (NCED), which catalyzes the oxidative cleavage of either $9^{\prime}$-cisneoxanthin or 9-cis-violaxanthin (Schwartz et al., 1997; Tan et al., 1997). NCED genes have been then identified in a number of other plant species (Nambara and Marion-Poll, 2005). In Arabidopsis, VP14-related gene family is composed of nine members, five of which (NCED2, NCED3, NCED5, NCED6, and NCED9) encode xanthoxin-producing enzymes (Iuchi et al., 2001; Toh et al., 2008).

In Arabidopsis plastids, ZEP is associated mainly to envelope and slightly to thylakoid membranes (Figure 1). In contrast 
NSY/ABA4 is presumably tightly bound to the envelope since this protein is predicted to contain four transmembrane domains and is exclusively found in the envelope fraction (Joyard et al., 2009). In contrast, NCED proteins have been detected either in stroma or thylakoid membrane-bound compartments, or both (Tan et al., 2003). In addition, recent VP14 structural analysis suggested that this enzyme might penetrate the surface of thylakoid membrane to access and transfer carotenoid substrates to its catalytic center (Messing et al., 2010). The scattered location of ZEP, NSY, and NCED suggests that the production of xanthoxin inside plastids may require transport mechanisms of lipid-soluble carotenoid molecules, which are not currently understood. Since the following enzymatic reactions take place in the cytosol, xanthoxin is also presumed to migrate from plastid to cytosol by a still unknown mechanism.

Abscisic aldehyde is synthesized from xanthoxin, by an enzyme belonging to short-chain dehydrogenase/reductase family, which is named SDR1 and is encoded by the ABA2 gene in Arabidopsis (Rook et al., 2001; Cheng et al., 2002; Gonzalez-Guzman et al., 2002). The oxidation of the ABA-aldehyde is the final step of ABA biosynthesis, and is catalyzed by an abscisic aldehyde oxidase. In Arabidopsis, four homologous aldehyde oxidase $(A A O)$ genes have been characterized, but only one of them, $A A O 3$, encodes a protein that has proven activity on abscisic aldehyde (Seo et al., 2000). Activity of this molybdoenzyme requires the activation of its molybdenum co-factor (Moco) by addition of a sulfur atom to the Mo center, which is catalyzed by a Moco sulfurase, which has been named ABA3 in Arabidopsis (Bittner et al., 2001; Xiong et al., 2001).

\section{ABA CATABOLISM}

Abscisic acid inactivation is a crucial mechanism to fine-tune ABA levels, which occurs by either oxidation or conjugation (Figure 1). The major catabolic route is the 8 -hydroxylation of ABA by the CYP707A subfamily of P450 monooxygenases (Kushiro et al., 2004; Saito et al., 2004). Spontaneous 8'-hydroxy-ABA isomerization gives rise to phaseic acid (PA), which is then converted to dihydrophaseic acid (DPA) by a still unknown reductase. ABA can also be hydroxylated at the $\mathrm{C}-7^{\prime}$ and $\mathrm{C}-9^{\prime}$ positions. As $8^{\prime}-$ hydroxylation, $9^{\prime}$-hydroxylation is catalyzed by CYP707A as a side reaction, and neoPA is then formed by spontaneous isomerization (Zhou et al., 2004; Okamoto et al., 2011). The conjugation of ABA with glucose to form the ABA-glucose ester (ABA-GE) is catalyzed by an ABA glucosyltransferase, and in Arabidopsis only UGT71B6 exhibits a selective glucosylation activity toward the natural enantiomer (+)-ABA (Lim et al., 2005; Priest et al., 2006). Subsequent hydrolysis of conjugates constitutes an alternative pathway for ABA synthesis in response to dehydration stress. Two glucosidases BG1 and BG2, localizing respectively in the endoplasmic reticulum or the vacuole, have been identified (Lee et al., 2006; Xu et al., 2012).

Deficiency in either ABA synthesis or ABA inactivation by $8^{\prime}$-hydroxylation leads to strong dormancy phenotypes, respectively dormancy loss or strengthening (Nambara and MarionPoll, 2005; Seo etal., 2009; Nambara etal., 2010). In contrast, reports on functional analysis of mutant or overexpressing lines in ABA conjugation or ABA-GE hydrolysis did not yet describe the implication of these processes in dormancy control.
Nevertheless, ABA conjugation may contribute to ABA breakdown upon germination, as shown in lettuce (Lactuca sativa; Chiwocha et al., 2003).

\section{ABA SIGNALING PATHWAY}

Genetic analyses suggest that PYR/PYL/RCAR (pyrabactin resistance1/PYR1-like/regulatory components of $\mathrm{ABA}$ receptor) $\mathrm{ABA}$ receptors, clade $\mathrm{A}$ type $2 \mathrm{C}$ protein phosphatases (PP2C) and group III sucrose non-fermenting1-related protein kinase2 (SnRK2) subfamily are essential core components of the upstream signal transduction network that regulates ABA-responsive processes, including dormancy and germination (reviewed in Cutler et al., 2010). PYR/PYL/RCAR proteins constitute a 14-member family, belonging to the START-domain superfamily, also called Bet v I-fold (Ma et al., 2009; Park et al., 2009). ABA binding induces receptor conformation changes allowing the formation of a protein complex with $\mathrm{PP} 2 \mathrm{C}$ and the inhibition of phosphatase activity (Figure 2). The clade A PP2C, including ABA INSENSITIVE1 (ABI1) and ABI2, also interact with three SnRK2 (SnRK2.2, SnRK2.3, and SnRK2.6) and, in the absence of ABA, dephosphorylate a serine residue whose phosphorylation is required for kinase activity (Soon et al., 2012). When ABA is present, PP2C binding to the receptor releases inhibition of SnRK2 activity, which can phosphorylate downstream targets.

Other types of receptors and a large number of genes, whose mutations alter ABA germination sensitivity, have been reported to participate in ABA signaling. In particular, regulatory mechanisms such as RNA processing, RNA/protein stability or chromatin remodeling have an important role. However, they will not be detailed here, since their role in ABA crosstalk with ethylene and $\mathrm{NO}$ in seeds still requires further investigation. In Arabidopsis seeds, extensive evidence including mutant phenotypes strongly supports a central role of the PYR/PYL, PP2C, SnRK2 complex in ABA signaling (reviewed in Cutler et al., 2010; Nambara et al., 2010). Germination of a $p y r / p y l$ sextuple mutant is highly insensitive to ABA, as also observed for the snrk2.2 snrk2.3 snrk2.6 triple mutant (Fujii and Zhu, 2009; Gonzalez-Guzman etal., 2012). Moreover the snrk2 triple mutant exhibits loss of dormancy and even seed vivipary under high humidity conditions (Nakashima et al., 2009). Conversely, in accordance with PP2C being negative regulators of $\mathrm{ABA}$ signaling, germination in triple $p p 2 c$ mutants was slower than in wild type and was inhibited by very low ABA concentrations (Rubio et al., 2009). In contrast, the gainof-function mutations abil-1 and abi2-1, which prevent PP2C binding to PYL/PYR/RCAR, lead to ABA insensitivity and reduced dormancy (Ma et al., 2009; Park et al., 2009).

Basic leucine zipper transcription (bZIP) factors of the ABARESPONSIVE ELEMENTS (ABRE) BINDING FACTOR/ABA RESPONSE ELEMENT BINDING FACTOR/ABA INSENSITIVE5 (ABF/AREB/ABI5) clade have been shown in different species to constitute SnRK2 downstream targets and regulate ABRE containing genes (Johnson et al., 2002; Kobayashi et al., 2005; Umezawa et al., 2009). Several family members are expressed at different seed stages and exhibit partially redundant or antagonistic functions, and ABI5 appears to have a predominant role in the regulation of a subset of late embryogenesis abundant (LEA) proteins during late seed development (Bensmihen et al., 2002; 


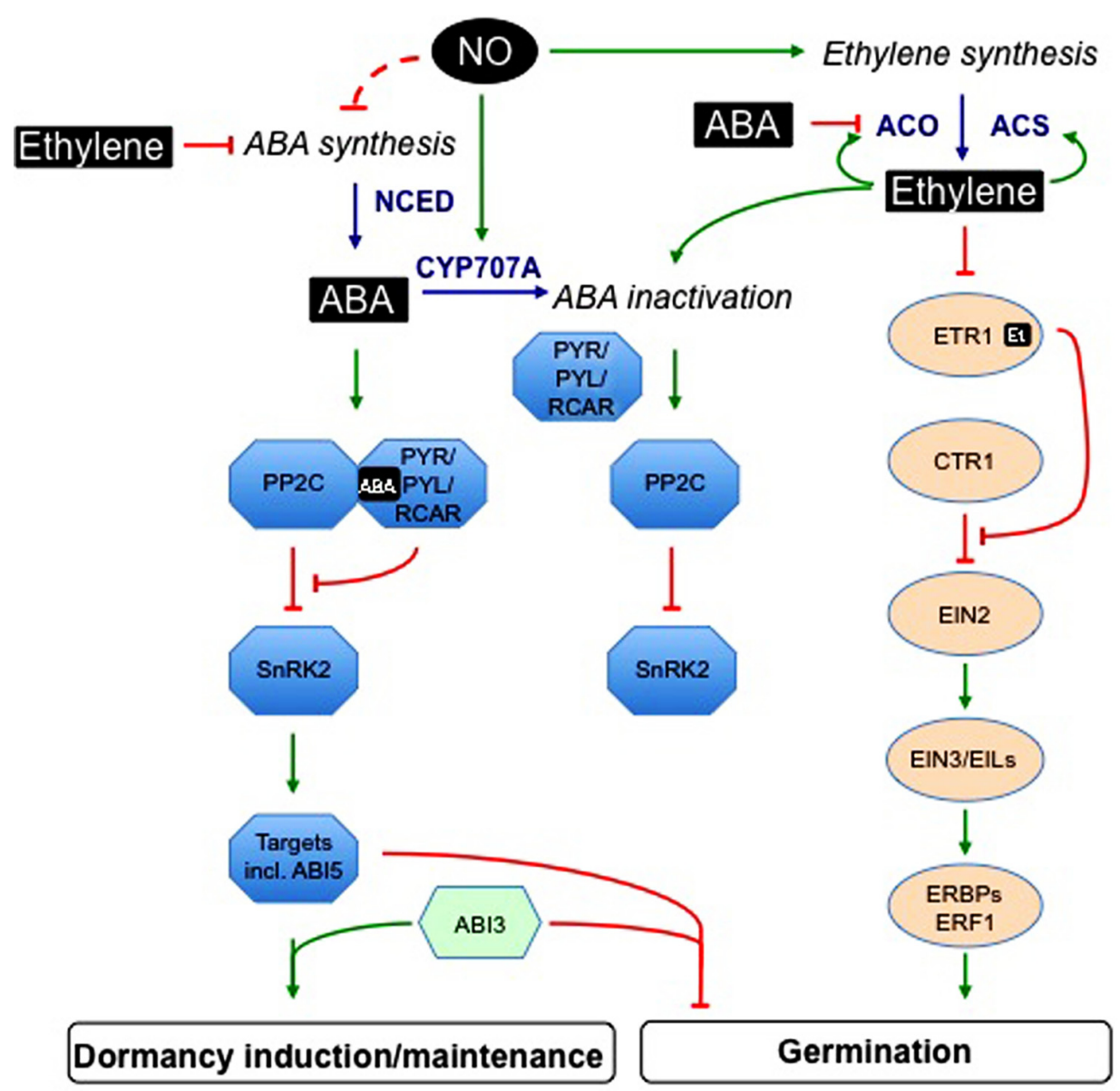

FIGURE 2 | Interactions between ethylene, abscisic acid, and nitric oxide signaling pathways in the regulation of seed germination and dormancy. This scheme is based on genetic analyses, microarray data, and physiological studies on seed responsiveness to $A B A$, ethylene, or NO. ABA binding to PYR/PYL/RCAR receptor induces the formation of a protein complex with $\mathrm{PP} 2 \mathrm{C}$ and the inhibition of phosphatase activity. In the absence of ABA, PP2C

dephosphorylate SnRK2. When ABA is present, PP2C binding to the receptor releases inhibition of SnRK2 activity, which can phosphorylate downstream targets, including ABI5-related transcription factors. Interactions between $A B I 3$ and $A B I 5$ mediate transcriptional regulation of ABA-responsive genes. Ethylene positively regulates its own biosynthesis, by acting on ACC synthesis catalyzed by ACS and subsequent conversion to ethylene by ACO. This last step is also subject to ABA inhibition. Ethylene is perceived by receptors (among which ETR1) located in the endoplasmic reticulum; its binding leads to the deactivation of the receptors that become enable to recruit CTR1. Release of CTR1 inhibition allows EIN2 to act as a positive regulator of ethylene signaling pathway. EIN2 acts upstream of nuclear transcription factors, such as EIN3, EILs, and ERBPs/ERFs. Ethylene down-regulates ABA accumulation by both inhibiting its synthesis and promoting its inactivation, and also negatively regulates ABA signaling. In germinating seeds, NO enhances ABA catabolism and may also negatively regulate $A B A$ synthesis and perception. Moreover, NO promotes both ethylene synthesis and signaling pathway. $A B A$, abscisic acid; $A B I 3, A B A$ insensitive3; $A B \mid 5, A B A$ insensitive5; $A C C$, 1-aminocyclopropane 1-carboxylic acid; ACO, ACC oxidase; ACS, ACC synthase; CTR1, constitutive triple response 1; CYP707A, ABA-8'-hydroxylase; EIL, EIN3-like; EIN, ethylene-insensitive; EREBP, ethylene-responsive element binding protein; ERF, ethylene response factor; Et, ethylene; ETR1, ethylene receptor 1; NCED, 9-cis-epoxycarotenoid dioxygenase; NO, nitric oxide; PP2C, clade A type $2 \mathrm{C}$ protein phosphatases; PYR/PYL/RCAR, pyrabactin resistance1/PYR1-like /regulatory components of ABA receptor; SnRK2, group III sucrose non-fermenting-1-related protein kinase 2; a dashed line is used when regulatory targets are not precisely identified.
Finkelstein et al., 2005). abi5 mutation confers ABA-insensitive germination, but it does not impair seed dormancy, suggesting that other factors might be involved in dormancy induction (Finkelstein, 1994). Nevertheless, ABI5 has been clearly proven to act as a major inhibitor of germination processes in imbibed seeds, notably through its up-regulation by stress-induced ABA accumulation (Lopez-Molina et al., 2001; Piskurewicz et al., 2008). ABI3/VIVIPAROUS1 (VP1) interacts with ABI5 for the regulation of a number of ABA-responsive genes during seed maturation and germination (Lopez-Molina et al., 2002; Piskurewicz et al., 2008,
2009). However, in contrast to abi5, abi3 mutants do not only exhibit ABA-resistant germination, but also other phenotypes including desiccation intolerance and precocious germination. They share these maturation defects with fusca3 (fus3) and leafy cotyledon2 (lec2) mutants, which, like abi3, carry mutations in B3 transcription factor family genes. These factors form a complex network regulating the expression of reserve storage and LEA genes by their binding to RY motif, and it has been suggested that the lack of dormancy induction in mutants might indirectly result from early seed developmental defects (Gutierrez et al., 2007; 
Finkelstein et al., 2008; Santos-Mendoza et al., 2008; Graeber et al., 2012). Nevertheless fus 3 mutation has been shown to affect ABA levels in developing seeds (Gazzarrini et al., 2004). In addition, ABA-specific phenotypes of abi3/vp1 mutants strongly suggest an involvement in ABA-regulated dormancy induction, but downstream dormancy genes still remain elusive. Nevertheless, one of these might be the recently identified seed dormancy4 ( $S d r 4$ ) gene in rice, which encodes a nuclear protein of unknown function (Sugimoto et al., 2010).

The Arabidopsis DELAY OF GERMINATION1 (DOG1) gene, whose precise function is still unknown, has been identified as a major regulator of seed dormancy (Bentsink et al., 2006). In accordance, protein accumulation in dry seeds well correlates with dormancy depth, and both transcript and protein levels are increased upon cool conditions of seed maturation, which increase seed dormancy (Kendall etal., 2011; Nakabayashi et al., 2012). Despite $\operatorname{dog} 1$ dormancy phenotypes are similar to ABA synthesis and signaling mutants, current evidence suggests that DOG1 and $A B A$ act in independent pathways. Nevertheless regulation of dormancy depth by DOG1 requires a functional ABA signaling pathway (Nakabayashi et al., 2012), and DOG1 has been reported to be implicated in the ABA-mediated sugar signaling pathway, together with ABI4, an APETALA2 transcription factor involved in reserve mobilization at germination (Penfield et al., 2006; Teng et al., 2008). Another mutation, named despierto (dep), also causes dormancy loss (Barrero et al., 2010). DEP gene encodes a C3HC4 RING (Really Interesting New Gene)-finger protein, whose targets are unknown. In addition to similarity in mutant phenotypes, expression of both $D E P$ and DOG1 genes is maximal during late seed development and decreases during imbibition. Moreover dep mutation reduces DOG1 transcript levels in developing seeds and vice versa. It also down-regulates the expression of several ABA biosynthesis and signaling genes, including NCED6, NCED9, and $A B I 3$, suggesting its action in dormancy induction may involve the ABA signaling pathway (Barrero et al., 2010).

\section{SPATIOTEMPORAL REGULATION OF ABA LEVEL AND SIGNALING IN DORMANCY AND GERMINATION}

Abscisic acid is produced in all seed tissues (testa, endosperm, embryo), as suggested by the spatiotemporal expression of ABA biosynthesis genes (Lefebvre et al., 2006; Frey et al., 2012). However, ABA accumulated in seeds also originates from synthesis in vegetative tissues and transport to the seed (Frey et al., 2004; Kanno et al., 2010). Several ABA transporters have been recently identified, which belong to either the ATP-binding cassette $(\mathrm{ABC})$ or nitrate transporter 1 (NRT1)/peptide transporter (PTR) families (Kang et al., 2010; Kuromori et al., 2010; Kanno et al., 2012). $\mathrm{ABC}$ transporter $\mathrm{G}$ family member 25 (ABCG25) functions as a plasma membrane ABA exporter, whereas both ABCG40 and AIT1 (ABA IMPORTER1) are plasma membrane uptake transporters. Despite mutations in these three genes induce alterations in germination sensitivity to $A B A$, suggesting a possible function in seeds, the precise contribution of any of them to either ABA supply from mother plant to seeds or its translocation between maternal and/or embryonic seed tissues needs further investigation. Another $A B C$ transporter gene, $\mathrm{ABCG} 22$, has been reported to be involved in ABA-regulated water stress tolerance, but its function in ABA transport remains uncertain (Kuromori et al., 2011). ABA levels are maximal during mid-seed development, with a large fraction produced in maternal tissues (Karssen et al., 1983; Kanno et al., 2010). Maternal $A B A$ has a major contribution to the regulation of many aspects of seed development, but only ABA produced by zygotic tissues at late maturation stages imposes dormancy (Karssen et al., 1983; Frey et al., 2004).

Carotenoid cleavage by NCED and ABA inactivation by CYP707A 8'-hydroxylase have been proven to constitute key regulatory steps for the control of ABA levels, which affect seed dormancy and germination in response to environmental cues (Nambara and Marion-Poll, 2005; Seo et al., 2009; Nambara et al., 2010). Among the five Arabidopsis NCED genes, NCED6 and NCED9 exhibit the highest expression levels in developing seeds and show distinctive expression patterns. NCED6 is specifically expressed in endosperm, whereas NCED9 expression is detected in testa and embryo. Furthermore mutant analysis indicated that ABA production in both embryo and endosperm contributes to dormancy induction (Lefebvre et al., 2006; Frey et al., 2012). In barley (Hordeum vulgare), the two HvNCED genes also exhibit differential spatiotemporal patterns of expression. In contrast to $H v N C E D 2, H v N C E D 1$ transcript levels vary depending on environmental conditions during grain development and modulate $\mathrm{ABA}$ accumulation at late maturation stages (Chono et al., 2006). ABA inactivation by CYP707A during seed maturation also regulates dry seed ABA levels and dormancy depth, as deduced from cyp707a mutant analysis (Okamoto et al., 2006). Moreover, the seed dormancy increase under cold-maturation conditions is not only correlated with DOG1 up-regulation, as mentioned above, but also with CYP707A2 down-regulation (Kendall et al., 2011).

Upon imbibition, dormancy maintenance and germination are also regulated by both ABA catabolism and neo-synthesis. A decrease in ABA levels at imbibition has been observed in both dormant and non-dormant seeds in several species; nevertheless dormant seeds maintain higher ABA levels and in accordance exhibit lower CYP707A transcript levels, as shown in Arabidopsis and barley (Millar et al., 2006). Barley HvABA8'OH1 transcripts were detected in coleorhiza cells near the root apex and Arabidopsis CYP707A2 in endodermis and micropylar endosperm next to the radicle (Millar et al., 2006; Okamoto et al., 2006). Moreover, it is well documented in several species that unfavorable light or temperature conditions prevent germination by coordinated regulation of NCED and CYP707A gene expression (Seo etal., 2006; Gubler etal., 2008; Toh etal., 2008; Leymarie et al., 2009; Argyris et al., 2011). Furthermore, dormancy cycling by seasonal variation of soil temperature has been recently linked to the regulation of $\mathrm{ABA}$ metabolism and signaling genes. Deep dormancy in winter is correlated with increased ABA levels and NCED6 expression, together with that of DOG1 and MOTHER OF FLOWERING LOCUS T (MFT). MFT encodes a phosphatidylethanolamine-binding protein, which is regulated by $A B I 3$ and $A B I 5$, and feedback regulates $A B A$ signaling by repressing $A B I 5$ (Xi et al., 2010). In contrast, shallow dormancy in summer is correlated with a reduction in $A B A$ levels and an up-regulation of CYP707A2 and ABI2, which negatively regulates ABA signaling (Footitt et al., 2011). 
In Arabidopsis, despite endosperm consists in a single cell layer in mature seeds, convergent evidence demonstrated its major role in ABA control of seed dormancy and germination. Firstly, whereas the removal of whole seed coat (endosperm and testa) releases mechanical constraints and allows development of embryos dissected from dormant seeds, the preservation of the endosperm after testa removal maintains dormancy (Bethke et al., 2007a). Secondly, using a "seed coat bedding assay," Lee et al. (2010) showed that diffusion of endospermic ABA from dormant seed envelopes could prevent growth of non-dormant embryos, including those of ABA-deficient aba2 mutants. In isolated embryos, translocated ABA was able to induce ABI5 protein accumulation, whose level was correlated with dormancy maintenance. In addition, in a previous study, $A B I 5$ transcript was detected in the embryo and the micropylar endosperm of imbibed seeds, suggesting a role in the inhibition of both embryo growth and endosperm rupture by ABA (Penfield et al., 2006). The tissue-specificity of ABA sensitivity is also likely regulated by the spatiotemporal expression of upstream ABA signaling components, as suggested by the differential expression of PYR/PYL genes in embryo and/or endosperm of imbibed seeds (Gonzalez-Guzman et al., 2012).

\section{ETHYLENE BIOSYNTHESIS, SIGNALING, AND ABA CROSSTALK IN SEED GERMINATION ETHYLENE BIOSYNTHESIS AND SIGNALING}

Ethylene biosynthesis pathway in germinating seeds is the same as that described in other plant organs (Figure 3), in which $S$-adenosyl-methionine (S-AdoMet) and 1-aminocyclopropane1-carboxylic acid (ACC) are the main intermediates (Yang and Hoffman, 1984; Wang et al., 2002; Rzewuski and Sauter, 2008). The first step of ethylene biosynthesis is the conversion of $S$-AdoMet to ACC catalyzed by ACC synthase ( $S$-adenosyl-Lmethionine methylthioadenosine-lyase, ACS), the by-product being $5^{\prime}$-methylthioadenosine (MTA), which is recycled back to methionine through the Yang cycle (Yang and Hoffman, 1984; Kende, 1993). The second step corresponds to the oxidation of ACC by ACC oxidase (ACO) to form ethylene, $\mathrm{CO}_{2}$, and hydrogen cyanide $(\mathrm{HCN})$. Cyanide produced during this final step of ethylene synthesis is detoxified to $\beta$-cyanoalanine by $\beta$-cyanoalanine synthase ( $\beta$-CAS). Both ACS and ACO are encoded by a multigene family. In Arabidopsis, nine active ACS genes have been characterized (Yamagami etal., 2003; Wang et al., 2005; Dong et al., 2011). Most of them can be induced by cycloheximide (ACS2, ACS4, ACS6), wounding (ACS2, ACS4), and ethylene treatment (ACS2, ACS6; reviewed in Wang et al., 2002). In addition, ACS6 can also be induced by cyanide (Smith and Arteca, 2000) or ozone treatment (Vahala et al., 1998). ACO activity controls in vivo ethylene production and has fundamental contribution during seed germination (Matilla and Matilla-Vazquez, 2008; Linkies and Leubner-Metzger, 2012).

In Arabidopsis, five membrane-localized receptors have been identified: ethylene resistant 1 (ETR1), ETR2, ethylene response sensor 1 (ERS1), ERS2, and ethylene insensitive 4 (EIN4; Figure 2). Among them, ETR1 and ERS1 contain three transmembrane domains in the $\mathrm{N}$-terminus and a histidine kinase domain in the C-terminus. In contrast, ETR2, EIN4, and ERS2 have four transmembrane regions and a serine-threonine kinase domain in

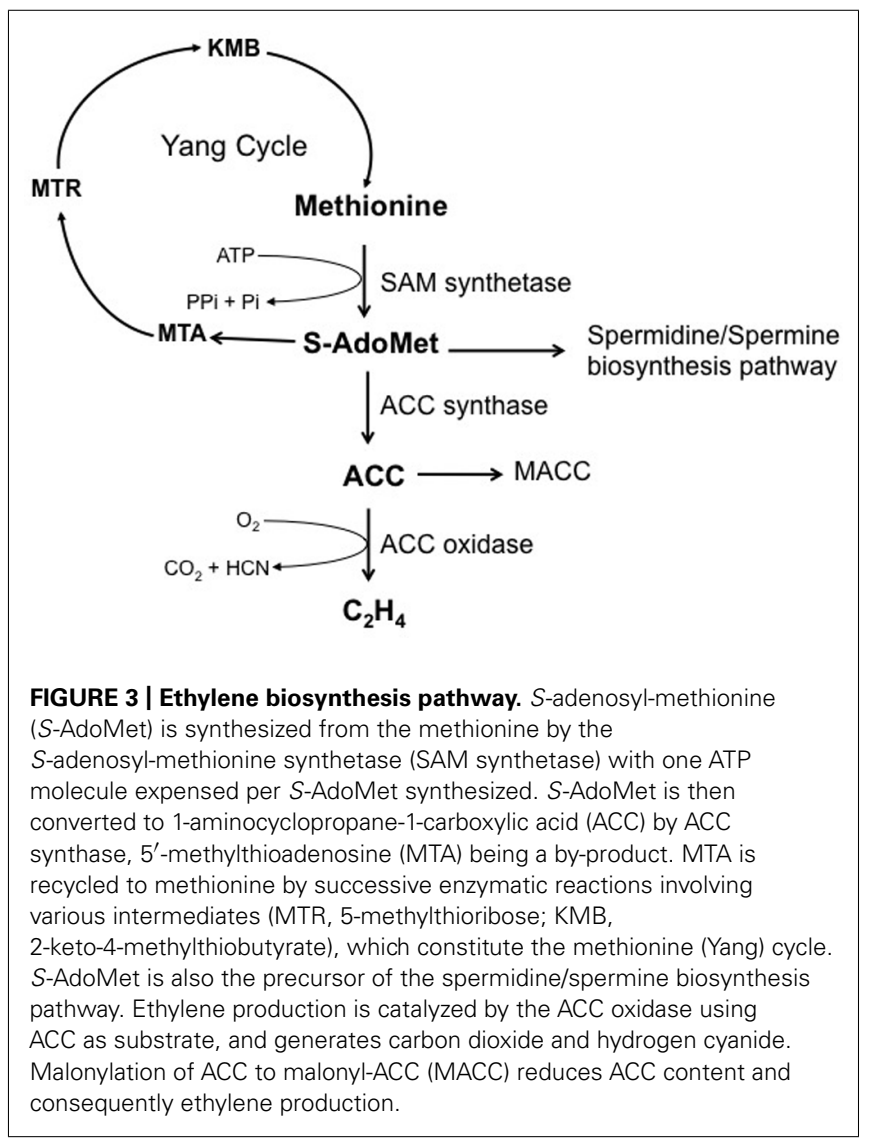

the C-terminus (Kendrick and Chang, 2008). Binding of $\mathrm{C}_{2} \mathrm{H}_{4}$ to the receptors occurs in the hydrophobic $\mathrm{N}$-terminal part of the receptor dimer and requires a copper co-factor (Hall et al., 2007). The signaling pathway of $\mathrm{C}_{2} \mathrm{H}_{4}$ is controlled by CTR 1 (constitutive triple response 1), a serine-threonine protein kinase that acts as a negative regulator, downstream of the receptor and upstream of EIN2. $\mathrm{C}_{2} \mathrm{H}_{4}$ binding results in the inactivation of the receptor-CTR1 complex, and in turn allows activation of a kinase cascade controlling EIN2 and its transcription factors in the nucleus such as EIN3, EIL1, ethylene-responsive element binding proteins (EREBPs)/ethylene-responsive factors (ERFs), which activate the transcription of ethylene-responsive genes (Wang et al., 2002; Liu et al., 2004; Rzewuski and Sauter, 2008; Yoo et al., 2008; Stepanova and Alonso, 2009). EIN2 works downstream of CTR1 and upstream of EIN3 (Alonso et al., 1999). Recently, Qiao et al. (2009) demonstrated that EIN2 protein level is regulated through its degradation by the proteasome in the presence of the hormone via 2 F-Box proteins ETP1 and ETP2; in the presence of $\mathrm{C}_{2} \mathrm{H}_{4}, \mathrm{ETP} 1$ and ETP2 levels are low, thus increasing EIN2 protein level.

\section{SEED RESPONSIVENESS TO EXOGENOUS ETHYLENE}

The influence of ethylene on seed germination is well documented (Corbineau and Côme, 1995; Kepczynski and Kepczynska, 1997; Matilla, 2000; Matilla and Matilla-Vazquez, 2008). Ethylene, ethephon (an ethylene-releasing compound), or ACC (the precursor of ethylene) stimulate seed germination in numerous 
species, among which several parasitic plants such as Orobanche ramosa (Chun et al., 1979) and some Striga species (Egley and Dale, 1970; Bebawi and Eplee, 1986). Application of ethylene promotes germination of either primary dormant or secondary dormant seeds (Table 1). It breaks seed coat-imposed dormancy in cocklebur (Xanthium pennsylvanicum; Katoh and Esashi, 1975; Esashi et al., 1978), subterranean clover (Trifolium subterraneum; Esashi and Leopold, 1969), Rumex crispus (Taylorson, 1979) and Arabidopsis (Siriwitayawan et al., 2003), and embryo dormancy in apple (Malus domestica; Kepczynski et al., 1977; Sinska and Gladon, 1984), sunflower (Helianthus annuus; Corbineau et al., 1990), and beechnut (Fagus sylvatica; Calvo et al., 2004a). It can also overcome thermodormancy in lettuce (Abeles, 1986) or secondary dormancy in sunflower (Corbineau et al., 1988), Amaranthus caudatus (Kepczynski et al., 1996a), and Amaranthus paniculatus (Kepczynski and Kepczynska, 1993). Likewise, it stimulates germination of non-dormant seeds placed in non-optimal conditions (Kepczynski and Kepczynska, 1997; Matilla, 2000). For example, it can overcome the inhibition of germination imposed by high temperatures (Abeles, 1986; Gallardo et al., 1991) or osmotic agents (Negm and Smith, 1978; Kepczynski and Karssen, 1985), and alleviates the salinity effect in numerous halophytes (Khan et al., 2009).

The stimulatory effect of exogenous ethylene increases with hormone concentration, and the efficient concentrations range from 0.1 to $200 \mu \mathrm{L} \mathrm{L}^{-1}$, depending on species and depth of their dormancy. Ethylene at $1.25 \mu \mathrm{L} \mathrm{L}^{-1}$ allows $100 \%$ germination of dormant Arabidopsis seeds incubated at $25^{\circ} \mathrm{C}$ in darkness, when dormant sunflower seeds required $12.5 \mu \mathrm{L} \mathrm{L}^{-1}$ to fully germinate at $15^{\circ} \mathrm{C}$. Breaking of dormancy during chilling of apple seeds, or during dry storage of sunflower achenes, results in an increasing sensitivity to ethylene (Sinska, 1989; Corbineau and Côme, 2003). In Stylosanthes humilis, non-dormant seeds are at least 50-fold more sensitive to ethylene than freshly harvested dormant ones (Ribeiro and Barros, 2006). Improvement of dormant seed germination does not require a continuous application of ethylene; a short treatment in the presence of this compound is sufficient to improve germination of dormant seeds in various species (Schönbeck and Egley, 1981; Corbineau and Côme, 2003; Kepczynski et al., 2003). Seed responsiveness to ethylene decreases during prolonged pre-incubation under conditions favoring the maintenance of dormancy, probably due to an induction of a secondary dormancy (Speer et al., 1974; Esashi et al., 1978; Jones and Hall, 1984; Corbineau and Côme, 2003).

\section{INVOLVEMENT OF ETHYLENE BIOSYNTHESIS AND SIGNALING IN SEED GERMINATION}

Ethylene production begins as the imbibition phase starts and increases with the germination progression. Its development differs among species (reviewed in Kepczynski and Kepczynska, 1997; Matilla, 2000; Matilla and Matilla-Vazquez, 2008), however, the radicle protrusion through the seed coat is always associated with a peak of ethylene release. A close relationship between the ability to produce ethylene and seed vigor has been reported in numerous species (Samimy and Taylor, 1983; Gorecki et al., 1991; Khan, 1994; Chonowski et al., 1997), and ACC-dependent $\mathrm{C}_{2} \mathrm{H}_{4}$ production was proposed as a marker of seed quality (Corbineau, 2012).

Table 1 | Species whose seed dormancy is broken by ethylene or ethephon, an ethylene-releasing compound, or 1-aminocyclopropane-1-carboxylic acid (ACC).

\begin{tabular}{|c|c|c|}
\hline Species & Type of dormancy & Reference \\
\hline \multirow[t]{2}{*}{ Amaranthus caudatus } & Primary and secondary dormancies & Kepczynski and Karssen (1985); \\
\hline & & Kepczynski et al. (1996a, 2003) \\
\hline Amaranthus paniculatus & Secondary dormancy & Kepczynski and Kepczynska (1993) \\
\hline Amaranthus retroflexus & Primary dormancy & Kepczynski etal. (1996b) \\
\hline Arabidopsis thaliana & Primary dormancy & Siriwitayawan et al. (2003) \\
\hline Arachis hypogaea & Primary dormancy & Ketring and Morgan (1969) \\
\hline Chenopodium album & Primary dormancy & Machabée and Saini (1991) \\
\hline Fagus sylvatica & Embryo primary dormancy & Calvo et al. (2004a) \\
\hline \multirow[t]{2}{*}{ Helianthus annuus } & Embryo primary dormancy & Corbineau et al. (1990) \\
\hline & Secondary dormancy & Corbineau et al. (1988) \\
\hline \multirow[t]{2}{*}{ Lactuca sativa } & Thermodormancy & Speer et al. (1974) \\
\hline & Secondary dormancy & Abeles (1986) \\
\hline \multirow[t]{2}{*}{ Pyrus malus } & Embryo primary dormancy & Kepczynski etal. (1977); \\
\hline & & Sinska and Gladon (1984) \\
\hline \multirow[t]{2}{*}{ Rumex crispus } & Primary and secondary dormancies & Taylorson (1979); \\
\hline & & Samimy and Khan (1983) \\
\hline Stylosanthes humilis & Primary dormancy & Ribeiro and Barros (2006) \\
\hline Trifolium subterraneum & Primary dormancy & Esashi and Leopold (1969) \\
\hline \multirow[t]{2}{*}{ Xanthium pennsylvanicum } & Primary and secondary dormancies & Katoh and Esashi (1975); \\
\hline & & Esashi et al. (1978) \\
\hline
\end{tabular}


Ethylene production depends on both ACS activity that modulates ACC content, and the activity of ACO, the key enzyme that converts ACC into ethylene. Evolution of ethylene production during germination is associated with an increase in ACO activity, as well as a progressive accumulation of ACS and ACO transcripts, with generally a sharp increase during endosperm rupture or/and radicle protrusion (Gomez-Jimenez et al., 1998; Matilla and Matilla-Vazquez, 2008; Linkies et al., 2009; Iglesias-Fernandez and Matilla, 2010; Linkies and LeubnerMetzger, 2012). In Sisymbrium officinale, SoACS7 level is very low during seed imbibition, a more notable expression being detected when endosperm rupture reached 50-100\%, whereas SoACO2 expression is detected at early stages during seed imbibition, and then rises during the germination process (IglesiasFernandez and Matilla, 2010). Similarly, expression of PsACO1 in pea (Pisum sativum; Petruzzelli et al., 2003) and BrACO1 in turnip (Brassica rapa; Rodriguez-Gacio et al., 2004) is maximal at radicle emergence. In two Brassicaceae species, Arabidopsis and Lepidium sativum, ACO1 and ACO2 have been demonstrated to be the major ACOs involved in ethylene synthesis in seeds (Linkies et al., 2009; Linkies and Leubner-Metzger, 2012). In Lepidium sativum, the correlation between ACO1 and ACO2 transcript accumulation with in vivo ACO enzyme activity suggests that $A C O$ is regulated at the transcriptional level during germination.

Ethylene has been shown to regulate its own synthesis by inducing ACO transcription (Lin et al., 2009). It is required for the stimulation of ACO gene expression in pea (Petruzzelli et al., 2000, 2003), beechnut (Calvo et al., 2004b), and turnip (Puga-Hermida et al., 2003). In contrast, expression of SoACS7 in Sisymbrium officinale and PsACS1 in pea is not affected (Petruzzelli et al., 2000, 2003; Iglesias-Fernandez and Matilla, 2010).

Induction of thermodormancy is often associated with a reduced ethylene production, which may result in chickpea (Cicer arietinum) from a greater ACC-malonyltransferase activity and an $S$-AdoMet channeling toward the polyamine pathway, thus reducing ethylene precursor availability (Martinez-Reina et al., 1996), or also from ACO activity inhibition, as observed in chickpea and sunflower (Corbineau et al., 1988; Gallardo et al., $1991)$. Incubation at high temperature $\left(35^{\circ} \mathrm{C}\right)$ of lettuce seeds induces a reduction in ethylene production (Prusinski and Khan, 1990), associated with a complete repression of LsACS1 and a reduced expression of ACO-A (homologous to AtACO4; Argyris et al., 2008).

In contrast, treatments (chilling, GA, HCN...) that break seed dormancy often lead to an increase in ethylene production (reviewed in Kepczynski and Kepczynska, 1997; Matilla and Matilla-Vazquez, 2008). Cyanide treatment, which breaks embryo dormancy in apple and sunflower, stimulates ethylene production (Oracz et al., 2008; Gniazdowska et al., 2010). In apple 5-dayold seedlings, it increases ACS and ACO activities (Bogatek et al., 2004), whereas in sunflower it reduces in vivo ACC-dependent ethylene production (i.e., in vivo ACO activity) and HaACS and HaACO expression (Oracz et al., 2008). However, in Arabidopsis, cold stratification down-regulates the expression of ACOs, but results in transient expression of ACS (Narsai et al., 2011; Linkies and Leubner-Metzger, 2012).
Studies using inhibitors of ACS activity (AVG: aminoethoxyvinylglycine; AOA: amino-oxyacetic acid), ACO activity $\left(\mathrm{CoCl}_{2} ; \alpha\right.$-AIB: $\alpha$-aminoisobutyric acid), or ethylene action $(2,5$ NBD: 2,5-norbornadiene; STS: silver thiosulfate) demonstrated that ethylene evolved by seeds plays a promotive role in germination and dormancy breakage (Kepczynski et al., 1977, 2003; Sinska and Gladon, 1989; Corbineau et al., 1990; Esashi, 1991; Longan and Stewart, 1992; Gallardo et al., 1994; Hermann et al., 2007). Conversely, application of exogenous ACC stimulates germination of various ethylene-sensitive seeds such as lettuce (Fu and Yang, 1983), sunflower (Corbineau et al., 1990), cocklebur (Satoh et al., 1984), Amaranthus caudatus (Kepczynski, 1986) and Amaranthus retroflexus (Kepczynski et al., 1996b), chickpea (Gallardo et al., 1994), sugar beet (Beta vulgaris; Hermann et al., 2007). Thermodormancy in lettuce, Amaranthus caudatus and chickpea is also reversed by exogenous ACC (Gallardo et al., 1996; Kepczynski etal., 2003). This stimulatory effect of ACC suggests that dormancy might be related to low $\mathrm{C}_{2} \mathrm{H}_{4}$ production due to insufficient levels of endogenous ACC, i.e., low ACS activity.

Analysis of mutant lines altered in ethylene biosynthesis and signaling pathway demonstrated the involvement of ethylene in regulating seed germination. Mutations in ETHYLENE RESISTANT1 (ETR1) and ETHYLENE INSENSITIVE2 (EIN2) genes result in poor germination and deeper dormancy compared to wild type, in contrast constitutive triple response1 (ctr1) seeds germinate slightly faster (Bleecker et al., 1988; Leubner-Metzger et al., 1998; Beaudoin et al., 2000; Subbiah and Reddy, 2010). ERFs genes might also play a key (pivotal) role in ethylene responsiveness and germination regulation (Leubner-Metzger et al., 1998; Pirrello et al., 2006). In beechnut, Jimenez et al. (2005) demonstrated that the expression of FsERF1, a transcription factor involved in $\mathrm{C}_{2} \mathrm{H}_{4}$ signaling and sharing high homology with Arabidopsis ERFs, increases during dormancy release in the presence of ethephon or after chilling. In sunflower, ERF1 expression is fivefold higher in non-dormant than in dormant embryos, and also markedly stimulated by gaseous HCN, which breaks dormancy (Oracz et al., 2008). Beechnut FsERF1 is almost undetectable in dormant seeds incubated under high temperature conditions that maintain dormancy, or in the presence of germination inhibitors, either ABA or AOA, an inhibitor of ethylene biosynthesis, but increases during moist chilling that progressively breaks dormancy (Mortensen et al., 2004; Jimenez et al., 2005). In tomato (Solanum lycopersicon), SlERF2 transcript accumulation is higher in germinating seeds than in non-germinating ones, and its overexpression in transgenic lines results in premature seed germination (Pirrello et al., 2006). Interestingly, in lettuce seeds, expression of genes involved in ethylene signaling (CTR1, EIN2, and ETR1) is less affected by high temperature than that of biosynthesis genes (ACS and ACO; Argyris et al., 2008).

\section{CROSSTALK BETWEEN ETHYLENE AND ABA Effect of ABA on ethylene metabolism}

The antagonistic interaction between $\mathrm{ABA}$ and $\mathrm{C}_{2} \mathrm{H}_{4}$ during germination was demonstrated in numerous species (Leubner-Metzger et al., 1998; Beaudoin et al., 2000; Ghassemian et al., 2000; Kucera etal., 2005; Matilla and Matilla-Vazquez, 
2008). In Arabidopsis and Lepidium sativum, ethylene counteracts the inhibitory effects of ABA on endosperm cap weakening and endosperm rupture (Linkies et al., 2009). ABA also increases the ethylene requirement to release primary and secondary dormancies (Kepczynski and Kepczynska, 1997; Corbineau and Côme, 2003; Kepczynski et al., 2003). Inhibition of germination by ABA is associated with a reduction in ethylene production (Kepczynski and Kepczynska, 1997; Matilla, 2000). ABA clearly inhibits in vivo ACO activity, and this inhibition correlates with a decreased accumulation of ACO transcripts (Bailly et al., 1992; Petruzzelli et al., 2000, 2003; Linkies et al., 2009). In Arabidopsis, the accumulation of $A C O 1$ transcripts in both the embryo and endosperm during germination is inhibited by ABA, and the high levels of ACO1 transcripts in ABA-insensitive mutants suggests the regulation of ACO expression by ABA (Penfield et al., 2006; Carrera et al., 2008; Linkies et al., 2009). In the embryo, ACO2 transcript accumulation is also inhibited by ABA (Penfield et al., 2006). In Lepidium sativum, inhibition of both ACO1 and ACO2 by ABA is restricted to the endosperm cap (Linkies et al., 2009). In accordance, microarray analysis in Arabidopsis aba2 mutant detected an up-regulation of ACO transcript accumulation (Cheng et al., 2009). Moreover, inhibition of shoot growth in tomato ABAdeficient mutants, flacca and notabilis, and in Arabidopsis aba2 results from increased ethylene production (Sharp et al., 2000; LeNoble et al., 2004). In contrast to pea, chickpea, Lepidium sativum, and Arabidopsis, there is an ABA-mediated up-regulation of ACC accumulation and ACO expression in sugar beet seeds (Hermann et al., 2007).

\section{Effect of ethylene on ABA metabolism and signaling}

Treatment with exogenous ethylene or ACC does not affect ABA content nor expression of genes involved in ABA biosynthesis in Lepidium sativum (Linkies et al., 2009) and sugar beet (Hermann et al., 2007). Nevertheless, seeds of Arabidopsis ethylene-insensitive mutants, etr 1 and ein2, exhibit higher ABA content than wild type and consistently germinate more slowly (Kende et al., 1998; Beaudoin et al., 2000; Ghassemian et al., 2000; Chiwocha et al., 2005; Wang etal., 2007). ABA-GE levels are reduced in etr1-2 seeds; increased $\mathrm{ABA}$ accumulation might therefore be attributed to a decrease in ABA conjugation (Chiwocha et al., 2005). However, ethylene may also regulate other enzymatic steps, since a microarray analysis reported NCED3 up-regulation in ein2 and CYP707A2 down-regulation in etr1-1 (Cheng et al., 2009). High ABA levels in ein2 were also associated with an up-regulation of $A B A 1$ (Wang et al., 2007), which was, however, not detected on microarrays (Cheng et al., 2009).

Several reports suggest that, during germination, ethylene not only acts on $\mathrm{ABA}$ metabolism to reduce $\mathrm{ABA}$ levels, but also negatively regulates ABA signaling (Gazzarrini and McCourt, 2001; Kucera et al., 2005). Indeed, mutations that reduce ethylene sensitivity (e.g., etr1, ein2, and ein6) result in an increase in ABA sensitivity, while increased ethylene sensitivity in $\operatorname{ctr} 1$ and eto1 reduces ABA sensitivity (Beaudoin et al., 2000; Ghassemian et al., 2000; Brady and McCourt, 2003; Chiwocha et al., 2005; Kucera et al., 2005; Linkies et al., 2009; Subbiah and Reddy, 2010). Mutations in CTR1, for example, enhance the ABA insensitivity of abil-1 seeds, when $\mathrm{C}_{2} \mathrm{H}_{4}$-insensitive mutants like ein 2 reduce it
(Beaudoin et al., 2000). However, no significant difference in ABA sensitivity is observed in ein3, ein4, ein5, and ein7 (Subbiah and Reddy, 2010).

In addition, overexpression in Arabidopsis seeds of a beechnut tyrosine phosphatase, FsPTP1, reduces dormancy, through both ABA signaling down-regulation and EIN2 up-regulation, suggesting that the negative role of FsPTP1 in ABA signaling might result from modulation of $\mathrm{C}_{2} \mathrm{H}_{4}$ signaling (Alonso-Ramirez et al., 2011). This central role of EIN2 in mediating cross-links between hormonal response pathways has also been reported in plant response to abiotic and biotic stresses (Wang et al., 2007).

Despite the existence of interactions between the ABA and ethylene signaling pathways, genetic evidence indicates that they may mainly act in parallel, since double mutants obtained by crossing ethylene mutants (ctr1, ein1, ein3, and ein6) with the aba2 mutant exhibit phenotypes resulting from both ABA deficiency and altered ethylene sensitivity (Cheng et al., 2009).

\section{NITRIC OXIDE HOMEOSTASIS, SIGNALING AND CROSSTALK WITH ABA AND ETHYLENE NITRIC OXIDE: CHEMICAL NATURE AND REACTIVITY}

Nitric oxide is an inorganic, uncharged, gaseous free radical that can readily diffuse through cell membranes. Upon production, released NO can adjust to the cellular redox environment leading to the formation of diverse biologically active compounds referred to as reactive nitrogen species (RNS; Stamler etal., 1992). Thus, its biological half-life is assumed to be in the order of seconds depending on the redox environment and the initial amount (Saran etal., 1990). While NO production can be beneficial at relatively low levels, uncontrolled accumulation, referred to as nitrosative stress, can result in detrimental consequences in plant cells. A strict control of $\mathrm{NO}$ levels is therefore required for cell survival. The regulation of NO biosynthesis, localization, and duration along with the control of NO removal (or storage) is therefore of paramount importance in determining the biological consequences of NO accumulation and thus for its role as secondary messenger (Besson-Bard et al., 2008; Moreau et al., 2010; Baudouin, 2011). The chemical reactivity of $\mathrm{NO}$ makes it an unusual signal molecule that can readily act on a wide range of targets, especially proteins (Besson-Bard et al., 2008). The signal it mediates can also be modulated along the signal transduction pathways depending on the biological environment, thus adding to the complexity of $\mathrm{NO}$ signaling.

\section{THE DISTINCT PATHWAYS FOR NITRIC OXIDE BIOSYNTHESIS IN PLANTS AND THEIR RELATIVE CONTRIBUTION IN SEEDS}

Due to their importance as basis for NO-mediated signaling, the biosynthesis pathways of NO in plants have been the subjects of intense investigations during the last decade (Besson-Bard et al., 2008; Corpas et al., 2009; Moreau et al., 2010; Gupta et al., 2011). The existence of several sources of NO associated with enzymatic or non-enzymatic reactions has been reported but only a few have been completely elucidated so far. Here we will mainly focus on the reactions proven or suggested to be relevant in the context of seed physiology (Figure 4), as NO synthesis was previously reviewed in Simontacchi et al. (2007) and Sirova et al. (2011). 


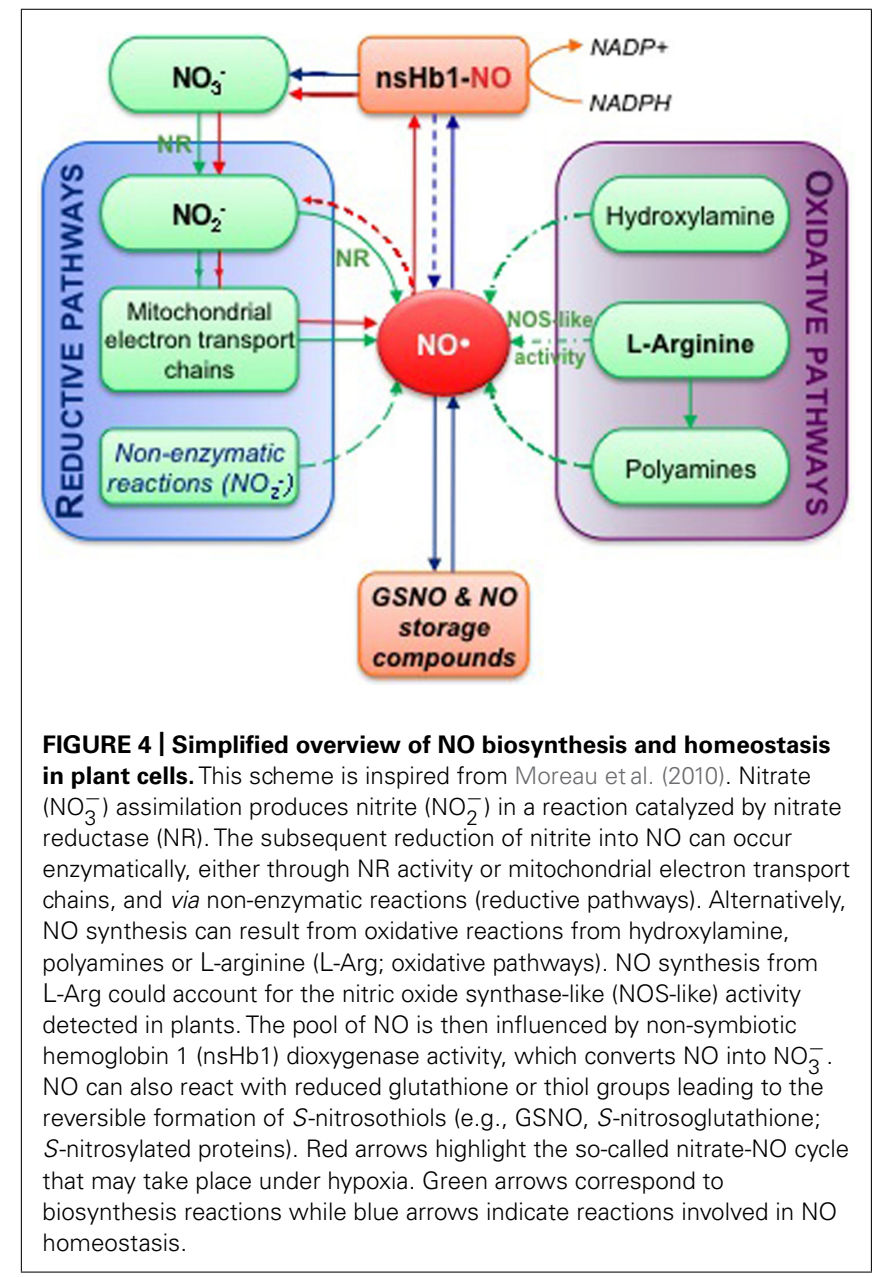

\section{Nitric oxide synthase-like activity}

In animals, NO biosynthesis is mainly catalyzed by three isoforms of NO synthase (NOS; Alderton et al., 2001). These enzymes metabolize L-arginine (L-Arg) into L-citrulline and NO via the following reaction:

$$
\begin{aligned}
& \text { L-Arg }+\mathrm{NAD}(\mathrm{P}) \mathrm{H}, \mathrm{H}^{+}+\mathrm{O}_{2} \Rightarrow \\
& \text { L-citrulline }+\mathrm{NAD}(\mathrm{P})^{+}+\mathrm{H}_{2} \mathrm{O}+\mathrm{NO}
\end{aligned}
$$

To date, despite the identification of a green alga NOS (Foresi et al., 2010), the search for a NOS homolog enzyme in higher plants only encountered failure, although biochemical assay highlighted the existence of a NOS-like activity in several plant tissues and organelles (Fröhlich and Durner, 2011). Moreover, exogenous application of NOS inhibitors (structural analogs of L-Arg such as L-NAME, $N$-nitro-L-arginine methyl ester) significantly reduced NO release under diverse conditions in several plant species (Crawford, 2006). Using these approaches, a NOS-like activity was detected in sorghum (Sorghum bicolor) and soybean (Glycine max) imbibed seeds (Simontacchi et al., 2007). Nonetheless, the liability of such proofs is now debated in light of the discovery of other L-Arg-dependent NO synthesis pathways (Tun et al., 2006). Moreover, the recent finding that L-NAME can affect NO production by interfering with nitrate reductase (NR) activity discredits its use as a NOS inhibitor in plants (Rasul et al., 2012). Thus, after more than a decade of intense research in the area and despite the proven occurrence of L-Arg-dependent NO biosynthesis, the mere existence of NOS is now questioned in plants (Fröhlich and Durner, 2011).

\section{Nitrate reductase}

Apart from its well-known role in nitrate reduction and assimilation, the cytosolic NR has been shown to catalyze the reduction of nitrite to $\mathrm{NO}$, using $\mathrm{NAD}(\mathrm{P}) \mathrm{H}$ as electron donor, both in vitro and in vivo, via the following reaction (Yamasaki et al., 1999; Rockel et al., 2002):

$$
\mathrm{NAD}(\mathrm{P}) \mathrm{H}+3 \mathrm{H}_{3} \mathrm{O}^{+}+2 \mathrm{NO}_{2}^{-} \Rightarrow \mathrm{NAD}(\mathrm{P})^{+}+2 \mathrm{NO}+5 \mathrm{H}_{2} \mathrm{O}
$$

In vivo, NR would be responsible at least in part for the basal level of $\mathrm{NO}$ production with a low reduction efficiency (in the order of $1 \%$ of the total NR activity). However, the nitrite reductase activity of NR (NR-NiR) can drastically increase under certain conditions such as oxygen deprivation (Rockel et al., 2002). Overall, conditions leading to NR-mediated nitrite production exceeding the rate of nitrite removal can lead to a substantial increase in NO production by NR. Both the nitrate and nitrite reductase activities of NR are tightly controlled by post-translational modifications (PTM; Lillo et al., 2004; Park et al., 2011; Wang et al., 2011). In Arabidopsis, NR and NR-NiR activities are stimulated by sumoylation mediated by the E3 SUMO ligase AtSIZ1 (Park et al., 2011). Furthermore, the $\mathrm{H}_{2} \mathrm{O}_{2}$-induction of $\mathrm{NO}$ biosynthesis in Arabidopsis roots was recently proposed to depend on mitogen-activated protein kinase 6 (MPK6)-mediated phosphorylation of one of the NR isoforms (Ser 627 in Arabidopsis NIA2; Wang et al., 2010, 2011). Moreover, $\mathrm{NO}$ was reported to inhibit NR activity in wheat leaves (Rosales et al., 2011). In Arabidopsis seedlings, GA may also negatively regulate light-induced NR activity at post-translational level (Zhang et al., 2011).

Distinct studies reported an implication of NR in NO-mediated signal transduction pathways (Bright et al., 2006; Neill et al., 2008; Gupta et al., 2011). In seeds, the NO-mediated positive effect of $\mathrm{NO}_{2}^{-}$and $\mathrm{NO}_{3}^{-}$on dormancy release supports an involvement of nitrite-dependent reductive pathways in NO biosynthesis, possibly via NR-NiR activity or at least depending on NR activity in the case of exogenous $\mathrm{NO}_{3}^{-}$(Bethke et al., 2006b). Accordingly, NR activity was detected concomitantly with a NOS-like activity in soybean and sorghum embryonic axes, both enzymatic activities appeared to parallel the accumulation of NO upon seed imbibition (Simontacchi et al., 2007).

In Arabidopsis, NR is encoded by two homologous genes, NIA1 and NIA2 (Wilkinson and Crawford, 1991). The relative contribution of these two isoforms to NO production was suggested to differ with a possible predominant involvement of NIA1 in NO production (Baudouin, 2011). Despite NO has been demonstrated to break seed dormancy (Bethke et al., 2006b; Liu et al., 2009), NR involvement in Arabidopsis seed germination remains unclear. Two distinct research groups assessed the germination characteristics of the nialnia2 double mutant (also named $\mathrm{G}^{\prime} 4-3$ ), obtained by Wilkinson and Crawford (1993). In the first study, G'4-3 seeds 
were found to be less dormant than wild type seeds (Alboresi et al., 2005), but more dormant in the second (Lozano-Juste and Leon, 2010). Differences in culture environments of mother plants, germination conditions or duration of seed storage may explain these contrasted results (Clerkx et al., 2004; Matakiadis et al., 2009).

\section{Polyamines and hydroxylamines}

Upon exogenous application of the polyamines, spermine (spm) and spermidine (spd), a rapid NO production from Arabidopsis seedlings has been observed under aerobic conditions (Tun et al., 2006). In plants, the tri-amine Spd and tetra-amine Spm are formed by successive additions of aminopropyl groups [resulting from $S$-AdoMet decarboxylation] to the diamine putrescine (Put; reviewed in Wimalasekera etal., 2011a). Put can be synthesized either from L-Arg (by L-Arg decarboxylase) or from L-ornithine (by ornithine decarboxylase). However, as Arabidopsis lacks ornithine decarboxylase activity, polyamines are exclusively produced from L-Arg (Hanfrey et al., 2001). Thus, NO biosynthesis from polyamines can be considered as a L-Arg-dependent pathway in Arabidopsis.

Plant cells are also able to produce NO through hydroxylamine oxidation and this reaction is promoted by reactive oxygen species (ROS) accumulation (Rümer etal., 2009). Thus, NO might be responsible for the positive effect of exogenous hydroxylamines on seed germination (Hendricks and Taylorson, 1974). However, the relevance of such pathway to NO synthesis remains unclear.

\section{Nitric oxide production in the apoplast}

The existence of a root specific plasma membrane nitrite-NO reductase (Ni-NOR) was reported in tobacco (Nicotiana tabacum; Stöhr et al., 2001). This enzyme would catalyze the reduction of nitrite into $\mathrm{NO}$ in the apoplast and could act in tandem with a plasma membrane-bound NR (PM-NR; Eick and Stöhr, 2012). Its implication has been proposed in several physiological processes in roots (Stöhr and Stremlau, 2006), but has not been so far investigated in seeds.

The non-enzymatic reduction of nitrite to NO can also occur under acidic $\mathrm{pH}$ and could be promoted by the presence of reductants (Mallick et al., 2000):

$$
2 \mathrm{HNO}_{2} \Rightarrow \mathrm{NO}+\mathrm{NO}_{2}+\mathrm{H}_{2} \mathrm{O} \Rightarrow 2 \mathrm{NO}+2 \mathrm{O}_{2}+\mathrm{H}_{2} \mathrm{O}
$$

This non-enzymatic reaction may be of paramount importance in seeds as an intense NO production was observed during early Arabidopsis seed imbibition next to the aleurone layer (Liu et al., 2009). Sodium nitroprusside (SNP) releases dormancy by generating both $\mathrm{NO}$ and cyanide. In C24 dormant seeds, the cell impermeable NO scavenger, cPTIO (2-(4-carboxyphenyl)phenyl-4,4,5,5tetramethylimidazoline-1-oxyl 3-oxide), was demonstrated to efficiently impede SNP dormancy release, suggesting that the apoplast might be either an important pathway for NO movement or a site for NO production (Bethke et al., 2006b).

\section{Mitochondrial respiration}

Depending on the oxygen availability, several hemeproteins can either act as NO scavengers or NO producers. In hypoxic mitochondria, deoxyhemeproteins can catalyze a NR-independent nitrite reduction into $\mathrm{NO}$ using electrons from the electron transport chain (Planchet et al., 2005). The re-oxidation of NO into nitrite can then occur either non-enzymatically inside the mitochondria, or in the cytosol, through the nicotinamide adenine dinucleotide phosphate (NADPH)-dependent dioxygenase activity of class-1 non-symbiotic hemoglobin (nsHb1) that metabolizes NO into nitrate, which is subsequently reduced into nitrite by NR (Igamberdiev and Hill, 2004; Perazzolli et al., 2004). These reactions constitute the so-called hemoglobin-NO cycle (displayed in red in Figure 4; Igamberdiev etal., 2010). nsHb1 proteins participate in NO scavenging, thereby playing an essential role in NO homeostasis. Accordingly, modulation of nsHbl expression in plants was shown to directly impact NO levels at distinct developmental stages including in seeds (Hebelstrup and Jensen, 2008; Thiel et al., 2011) and in diverse environmental conditions (Dordas, 2009; Cantrel et al., 2011).

The very active mitochondrial respiration upon seed imbibition may result in an oxygen consumption exceeding the atmospheric diffusion, thus leading to localized hypoxia in germinating seeds (Benamar et al., 2008). In such conditions, nitrite-dependent NO production may occur in mitochondria and modulate respiration through reversible NO-mediated inhibition of cytochrome $c$ oxidase (COX), thereby regulating oxygen consumption to avoid anoxia (Benamar etal., 2008). Therefore, this nitritedependent $\mathrm{NO}$ biosynthesis in mitochondria may be of significant importance in germinating seeds. However, its possible role in NO-mediated dormancy release has not yet been established.

Overall, current evidence supports the co-existence of several distinct NO biosynthesis pathways in seeds. Their relative contribution is probably highly dependent on both oxygen and ROS levels that may change along the time-course of imbibition. Further investigations will be required to elucidate the regulation of $\mathrm{NO}$ accumulation during seed imbibition.

\section{S-nitrosoglutathione: a reversible "storage" pool of nitric oxide?}

As for plant hormones, any mechanism directly influencing $\mathrm{NO}$ levels besides biosynthesis pathways may have a pivotal role in the regulation of $\mathrm{NO}$ signaling. In particular, since $\mathrm{NO}$ can react with reduced glutathione (GSH) to form S-nitrosoglutathione (GSNO), GSNO has been proposed to constitute a storage and transport form for NO in plants and seeds (Sakamoto et al., 2002). Such modulation of NO storage pool would have a significant impact on NO levels. GSNO can further be metabolized by the GSNO reductase (GSNOR). Accordingly, gsnor mutants have multiple phenotypes suggesting GSNOR involvement in several growth and developmental processes including seed germination (Lee et al., 2008; Holzmeister et al., 2011; Kwon et al., 2012).

\section{MOLECULAR TARGETS OF NITRIC OXIDE IN SEEDS}

Due to its chemical nature, NO is highly reactive and can interact with diverse molecules in plant cells. A number of NO-regulated genes have been identified in plants (Besson-Bard etal., 2009). These genes encode proteins involved in a wide range of functions from signal transduction to stress responses. However, the main challenge remains to pinpoint the direct molecular targets of NO, which are still poorly documented in plants. However, it is generally assumed that proteins constitute direct relevant NO targets. 
Besides its capacity to bind to transition metals of metalloproteins, NO can cause protein PTM, such as cysteine $S$-nitrosylation or tyrosine nitration (Moreau et al., 2010). These modifications remain poorly characterized in plants and particularly in seeds. However, as discussed below, there is strong experimental evidence indicating that NO signaling in seeds could principally rely on PTM of specific proteins (Delledonne, 2005).

Many $S$-nitrosylated proteins identified in plants are implicated in various metabolic processes (Lindermayr et al., 2005; Abat et al., 2008; Romero-Puertas et al., 2008; Tanou et al., 2009; Palmieri et al., 2010). In dry Arabidopsis seeds, a $\beta$-subunit of the mitochondrial ATP synthase complex was found to be $S$-nitrosylated, suggesting that NO could participate in the regulation of the seed energy status (Arc et al., 2011). In wheat seeds, a parallel increase in NO and protein $S$-nitrosylation was reported during sensu stricto germination (Sen, 2010). At least 13 modified proteins were detected, but not identified. In recalcitrant Antiaris toxicaria seeds, desiccation impedes subsequent germination by enhancing $\mathrm{H}_{2} \mathrm{O}_{2}$ accumulation (Bai et al., 2011). This stress is associated with an increased carbonylation and a reduced $S$-nitrosylation of the antioxidant enzymes of the ascorbate-GSH pathway. Conversely, NO pre-treatments promote germination of desiccated seeds through PTM pattern reversion that enhances antioxidant enzyme activities (Bai et al., 2011). The balance between carbonylation and $S$-nitrosylation of these proteins was proposed to act as molecular switch tuning their activity according to the redox environment (Lounifi et al., 2013).

\section{CROSSTALK BETWEEN NO, ETHYLENE, AND ABA}

In stomatal guard cells, ABA-induced stomatal closure is mediated by the successive accumulation of ROS and NO, acting as secondary messengers in ABA signaling (Neill et al., 2008). Even though similar actors are present in seeds, the picture is quite different, as both ROS and NO counteract ABA-inhibition of seed dormancy release and germination (Bethke et al., 2006b; Liu et al., 2010). This obvious discrepancy of NO action between seeds and stomata highlights the specificity of the seed signaling pathways (Figure 2).

In imbibed seeds, the application of ABA biosynthesis inhibitors, fluridone or norflurazon, reduces ABA neo-synthesis and promotes dormancy release and germination. In tomato seeds, the NO scavenger, cPTIO, was shown to prevent germination stimulation by fluridone (Piterkova et al., 2012). Conversely, in dormant Arabidopsis C24 seeds, SNP enhances the positive effect of norflurazon on germination and also decreases seed sensitivity to exogenous ABA (Bethke et al., 2006a). Taken together, these results suggest that $\mathrm{NO}$ reduces both $\mathrm{ABA}$ accumulation and sensitivity. In agreement, pharmacological experiments demonstrated that NO enhances CYP707A2 gene expression in Arabidopsis seeds (Liu et al., 2009). Indeed, during the first stage of seed imbibition, a rapid accumulation of NO, possibly at the endosperm layer, was suggested as required for rapid ABA catabolism and dormancy breaking. A similar NO accumulation during imbibition was also observed in germinating seeds from other species (Simontacchi et al., 2007). Recently, in Arabidopsis, NO was suggested to act upstream of GA in a signaling pathway leading to vacuolation of protein storage vacuoles in aleurone cells, a process inhibited by
ABA (Bethke et al., 2007a). Since the growth of isolated embryos was unaffected by NO donors or scavengers, the endosperm layer might be the primary site of NO synthesis and action in seeds, and in accordance was shown to perceive and respond to NO (Bethke et al., 2007a). Besides its effect on the hormonal balance, it has been speculated that NO may accelerate flux through the pentose phosphate pathway by indirectly increasing the oxidation of NADPH (Hendricks and Taylorson, 1974; Bethke et al., 2007b). An increase in glucose catabolism via this pathway may in turn promote dormancy release (Roberts and Smith, 1977).

Several lines of evidence suggest that NO crosstalk with ABA and ethylene may involve protein modifications. Among the proteins recently identified as candidates for a regulation by tyrosine nitration in Arabidopsis seedlings (Lozano-Juste et al., 2011), at least two may be involved in the interplay between $\mathrm{ABA}$ and NO in seeds. The first one is the Moco sulfurase ABA3 that catalyzes the conversion from the de-sulfo to the sulfo form of the Moco (Wollers et al., 2008). The de-sulfo form of Moco (also call the "oxo" form) is the co-factor of NR, involved in nitrite and NO generation in plants while the sulfo form is the cofactor of the aldehyde oxydase required for the last step of ABA synthesis (Mendel, 2007). If proven, modulation of ABA3 activity by nitration could affect the equilibrium between $\mathrm{ABA}$ and NO production in plants. The second protein is the E3 SUMO ligase AtSIZ1 recently demonstrated to stimulate NR and NR$\mathrm{NiR}$ activities, and negatively regulate ABA signaling by $\mathrm{ABI} 5$ sumoylation (Miura et al., 2009; Park et al., 2011). Thus, such modifications could have an important impact in seeds. Similarly, PTM contribution in the NO regulation of ethylene action has been also reported. In Arabidopsis, the up-accumulation of NO under hypoxia stimulates ethylene biosynthesis, possibly through PTM of key enzymes such as ACS and ACO by $S$-nitrosylation (Hebelstrup et al., 2012). In contrast, ethylene biosynthesis can be reversibly inhibited by NO through $S$-nitrosylation of methionine adenosyltransferase (MAT), leading to the reduction of the S-AdoMet pool (Lindermayr et al., 2006).

$S$-AdoMet is the precursor of ethylene and polyamines, thus a negative feedback regulation may exist between ethylene and the polyamine-dependent NO biosynthesis. Consistently, NO and ethylene accumulation are negatively correlated in ripe fruits (Manjunatha etal., 2012). In addition, exogenous Spm was shown to reduce ethylene production in apple seeds (Sinska and Lewandowska, 1991). Accordingly, an antagonism may exist between a positive polyamine effect mediated by $\mathrm{NO}$ and a negative effect due to a competition with ethylene biosynthesis for S-AdoMet. Furthermore, a copper amine oxidase (CuAO1) involved in polyamine catabolism has also been shown to regulate NO biosynthesis and participate to ABA signaling (Wimalasekera et al., 2011b). Indeed, seedlings of Arabidopsis cuaol mutant are impaired in both polyamine and ABA-induced NO synthesis, and mutant seeds also display a reduced sensitivity to exogenous ABA during germination (Wimalasekera et al., 2011b).

As mentioned above, in Brassicaceae species, ethylene positively regulates seed germination by stimulating the weakening and rupture of seed testa and endosperm by counteracting the inhibitory action of ABA on radicle protrusion (Linkies et al., 2009). In apple embryos, inhibition of ethylene biosynthesis prevents the 
promotion of dormancy release and germination by NO donors (Gniazdowska et al., 2007). Dormancy breaking of apple seeds by $\mathrm{NO}$ induces a transient production of ROS, stimulating ethylene accumulation thanks to an increase in both ACS and ACO activity (Gniazdowska et al., 2010). NO may also act on ethylene signaling since EREBPs were described as a class of transcription factors induced by NO (Parani et al., 2004). Moreover during tobacco seed germination, EREBP-3 that is transiently induced just before endosperm rupture is stimulated by ethylene and inhibited by ABA (Leubner-Metzger et al., 1998). Therefore, a synergic link seems to exist, at different levels, between NO and ethylene during seed germination, that counteracts $\mathrm{ABA}$ action.

\section{CONCLUSION}

Significant advances have been recently obtained in the understanding of the $\mathrm{ABA}$ and ethylene metabolism and signaling pathways. In contrast, current knowledge on NO biosynthesis, signaling and action is far too incomplete, especially in seeds, and would require further investigation. Future research efforts should also lead to the identification of downstream target genes of signaling components, in order to fully understand how $\mathrm{ABA}$ is able to induce and maintain dormancy, or ethylene to stimulate germination. Moreover unraveling the role of posttranslational mechanisms will be particularly crucial to developing a deeper understanding of hormonal pathways and deciphering NO regulatory network.

\section{REFERENCES}

Abat, J. K., Mattoo, A. K., and Deswal, R. (2008). S-nitrosylated proteins of a medicinal CAM plant Kalanchoe pinnata-ribulose-1,5-bisphosphate carboxylase/oxygenase activity targeted for inhibition. FEBS J. 275, 28622872.

Abeles, F. B. (1986). Role of ethylene in Lactuca sativa cv Grand Rapids seed germination. Plant Physiol. 81, 780-787.

Alboresi, A., Gestin, C., Leydecker, M. T., Bedu, M., Meyer, C., and Truong, H. N. (2005). Nitrate, a signal relieving seed dormancy in Arabidopsis. Plant Cell Environ. 28, 500-512.

Alderton, W. K., Cooper, C. E., and Knowles, R. G. (2001). Nitric oxide synthases: structure, function and inhibition. Biochem. J. 357, 593-615.

Alonso, J. M., Hirayama, T., Roman, G., Nourizadeh, S., and Ecker, J. R. (1999). EIN2, a bifunctional transducer of ethylene and stress responses in Arabidopsis. Science 284, 21482152.

Alonso-Ramirez, A., Rodriguez, D., Reyes, D., Jimenez, J. A., Nicolas, G., and Nicolas, C. (2011). Functional analysis in Arabidopsis of FsPTP1, a tyrosine phosphatase from beechnuts, reveals its role as a negative regulator of $\mathrm{ABA}$ signaling and seed dormancy and suggests its involvement in ethylene signaling modulation. Planta 234, 589-597.

Arc, E., Galland, M., Cueff, G., Godin, B., Lounifi, I., Job, D., et al. (2011). Reboot the system thanks to protein post-translational modifications and proteome diversity: how quiescent seeds restart their metabolism to prepare seedling establishment. Proteomics 11, 1606-1618.

Argyris, J., Dahal, P., Hayashi, E., Still, D. W., and Bradford, K. J. (2008) Genetic variation for lettuce seed thermoinhibition is associated with temperature-sensitive expression of abscisic acid, gibberellin, and ethylene biosynthesis, metabolism, and response genes. Plant Physiol. 148, 926-947.

Argyris, J., Truco, M. J., Ochoa, O., McHale, L., Dahal, P., Van Deynze, A., etal. (2011). A gene encoding an abscisic acid biosynthetic enzyme (LsNCED4) collocates with the high temperature germination locus Htg6.1 in lettuce (Lactuca sp.). Theor. Appl. Genet. 122, 95-108.

Audran, C., Liotenberg, S., Gonneau, M., North, H., Frey, A., TapWaksman, K., et al. (2001). Localisation and expression of zeaxanthin epoxidase mRNA in Arabidopsis in response to drought stress and during seed development. Aust. J. Plant Physiol. 28, 1161-1173.

Nitric oxide and ethylene crosstalk with ABA involves interactions at multiple levels in metabolism and signaling pathways. It would be important to discriminate the hierarchy among these signaling pathways, identify major regulatory nodes and determine whether the environmental factors, which regulate germination and dormancy, modulate this hierarchy.

Moreover, control of seed dormancy and germination involves distinct physiological processes, in tissues of different origin, to achieve a coordinated regulation of embryo arrest or growth and surrounding structure maintenance or rupture. Although hormonal signaling networks in seeds and whole plants share common components, sets of specific regulatory factors, among which only few are known, are likely working in restricted seed territories. Current research combining genetic tools and recent technologies including microdissection, transcriptome profiling, high-throughput proteomics, metabolomics, and system biology, should help to identify missing regulatory components and unravel complex interactions between signal transduction pathways.

\section{ACKNOWLEDGMENTS}

This work was supported by ANR-blanc ABSIG (2010-BLAN-1233 01) to Annie Marion-Poll and Julien Sechet and by a doctoral fellowship from the French Ministry of Higher Education and Research to Erwann Arc.

Bai, X., Yang, L., Tian, M., Chen, J., Shi, J., Yang, Y., et al. (2011). Nitric oxide enhances desiccation tolerance of recalcitrant Antiaris toxicaria seeds via protein $S$-nitrosylation and carbonylation. PLoS ONE 6:e20714. doi: 10.1371/journal.pone.0020714

Bailly, C., Corbineau, F., and Côme, D. (1992). The effects of abscisic acid and methyl jasmonate on 1-aminocyclopropane 1-carboxylic acid conversion to ethylene in hypocotyl segments of sunflower seedlings, and their control by calcium and calmodulin. Plant Growth Regul. 11, 349-355.

Barrero, J. M., Millar, A. A., Griffiths, J., Czechowski, T., Scheible, W. R., Udvardi, M., et al. (2010). Gene expression profiling identifies two regulatory genes controlling dormancy and ABA sensitivity in Arabidopsis seeds. Plant J. 61, 611-622.

Baskin, J. M., and Baskin, C. C. (2004). A classification system for seed dormancy. Seed Sci. Res. 14, 1-16.

Baudouin, E. (2011). The language of nitric oxide signalling. Plant Biol. 13, 233-242.

Beaudoin, N., Serizet, C., Gosti, F., and Giraudat, J. (2000). Interactions between abscisic acid and ethylene signaling cascades. Plant Cell 12, 1103-1115.
Bebawi, F. F., and Eplee, R. E. (1986). Efficacy of ethylene as a germination stimulant of Striga hermonthica. Weed Sci. 34, 694-698.

Benamar, A., Rolletschek, H., Borisjuk, L., Avelange-Macherel, M. H., Curien, G., Mostefai, H. A., et al. (2008). Nitrite-nitric oxide control of mitochondrial respiration at the frontier of anoxia. Biochim. Biophys. Acta 1777, 1268-1275.

Bensmihen, S., Rippa, S., Lambert, G., Jublot, D., Pautot, V., Granier, F., et al. (2002). The homologous ABI5 and EEL transcription factors function antagonistically to fine-tune gene expression during late embryogenesis. Plant Cell 14, 1391-1403.

Bentsink, L., Jowett, J., Hanhart, C. J., and Koornneef, M. (2006). Cloning of DOG1, a quantitative trait locus controlling seed dormancy in Arabidopsis. Proc. Natl. Acad. Sci. U.S.A. 103, 17042-17047.

Bentsink, L., and Koornneef, M. (2008). Seed dormancy and germination. Arabidopsis Book 6:e0119. doi: 10.1199/tab.0119

Besson-Bard, A., Astier, J., Rasul, S., Wawer, I., Dubreuil-Maurizi, C., Jeandroz, S., etal. (2009). Current view of nitric oxide-responsive genes in plants. Plant Sci. 177, 302-309.

Besson-Bard, A., Pugin, A., and Wendehenne, D. (2008). New insights into 
nitric oxide signaling in plants. Annu. Rev. Plant Biol. 59, 21-39.

Bethke, P. C., Libourel, I. G. L., Aoyama, N., Chung, Y. Y., Still, D. W., and Jones, R. L. (2007a). The Arabidopsis aleurone layer responds to nitric oxide, gibberellin, and abscisic acid and is sufficient and necessary for seed dormancy. Plant Physiol. 143, 1173-1188.

Bethke, P. C., Libourel, I. G. L., and Jones, R. L. (2007b). "Nitric oxide in seed dormancy and germination," in Annual Plant Reviews, Vol. 27, Seed Development, Dormancy and Germination, eds K. Bradford and H. Nonogaki (Oxford: Blackwell Publishing Ltd), 153-175.

Bethke, P. C., Libourel, I. G. L., and Jones, R. L. (2006a). Nitric oxide reduces seed dormancy in Arabidopsis. J. Exp. Bot. 57, 517-526.

Bethke, P. C., Libourel, I. G. L., Reinohl, V., and Jones, R. L. (2006b). Sodium nitroprusside, cyanide, nitrite, and nitrate break Arabidopsis seed dormancy in a nitric oxide-dependent manner. Planta 223, 805-812.

Bewley, J. D. (1997). Seed germination and dormancy. Plant Cell 9, 1055-1066.

Bittner, F., Oreb, M., and Mendel, R. R. (2001). ABA3 is a molybdenum cofactor sulfurase required for activation of aldehyde oxidase and xanthine dehydrogenase in Arabidopsis thaliana. J. Biol. Chem. 276, 4038140384.

Bleecker, A. B., Estelle, M. A., Somerville, C., and Kende, H. (1988). Insensitivity to ethylene conferred by a dominant mutation in Arabidopsis thaliana. Science 241, 10861089.

Bogatek, R., Sykala, A., and Krysiak, C. (2004). Cyanide-induced ethylene biosynthesis in dormant apple embryos. Acta Physiol. Plant. 26, 16.

Brady, S. M., and McCourt, P. (2003). Hormone cross-talk in seed dormancy. J. Plant Growth Regul. 22, 25-31.

Bright, J., Desikan, R., Hancock, J. T., Weir, I. S., and Neill, S. J. (2006). ABAinduced NO generation and stomatal closure in Arabidopsis are dependent on H2O2 synthesis. Plant J. 45, 113-122.

Cadman, C. S. C., Toorop, P. E., Hilhorst, H. W. M., and FinchSavage, W. E. (2006). Gene expression profiles of Arabidopsis Cvi seeds during dormancy cycling indicate a common underlying dormancy control mechanism. Plant J. 46, 805-822.

Calvo, A. P., Nicolas, C., Lorenzo, O., Nicolas, G., and Rodriguez, D. (2004a). Evidence for positive regulation by gibberellins and ethylene of ACC oxidase expression and activity during transition from dormancy to germination in Fagus sylvatica L. seeds. J. Plant Growth Regul. 23, 44-53.

Calvo, A. P., Nicolas, C., Nicolas, G., and Rodriguez, D. (2004b). Evidence of a cross-talk regulation of a GA 20 oxidase (FsGA20ox1) by gibberellins and ethylene during the breaking of dormancy in Fagus sylvatica seeds. Physiol. Plant. 120, 623-630.

Cantrel, C., Vazquez, T., Puyaubert, J., Reze, N., Lesch, M., Kaiser, W. M., et al. (2011). Nitric oxide participates in cold-responsive phosphosphingolipid formation and gene expression in Arabidopsis thaliana. New Phytol. 189, 415-427.

Carrera, E., Holman, T., Medhurst, A. Dietrich, D., Footitt, S., Theodoulou, F. L., et al. (2008). Seed after-ripening is a discrete developmental pathway associated with specific gene networks in Arabidopsis. Plant J. 142, 1493-1510.

Cheng, W. H., Chiang, M. H., Hwang, S. G., and Lin, P. C. (2009). Antagonism between abscisic acid and ethylene in Arabidopsis acts in paralle with the reciprocal regulation of their metabolism and signaling pathways. Plant Mol. Biol. 71, 61-80.

Cheng, W. H., Endo, A., Zhou, L., Penney, J., Chen, H. C., Arroyo, A., et al. (2002). A unique short-chain dehydrogenase/reductase in Arabidopsis glucose signaling and abscisic acid biosynthesis and functions. Plant Cell 14, 2723-2743.

Chiwocha, S. D. S., Abrams, S. R., Ambrose, S. J., Cutler, A. J., Loewen, M., Ross, A. R. S., et al. (2003). A method for profiling classes of plant hormones and their metabolites using liquid chromatographyelectrospray ionization tandem mass spectrometry: an analysis of hormone regulation of thermodormancy of lettuce (Lactuca sativa L.) seeds. Plant J. 35, 405-417.

Chiwocha, S. D. S., Cutler, A. J., Abrams, S. R., Ambrose, S. J., Yang, J., and Kermode, A. R. (2005). The ert1-2 mutation in Arabidopsis thaliana affects the abscisic acid, auxin, cytokinin and gibberellin metabolic pathways during maintenance of seed dormancy, moist-chilling and germination. Plant J. 42, 35-48.

Chono, M., Honda, I., Shinoda, S., Kushiro, T., Kamiya, Y., Nambara, E., etal. (2006). Field studies on the regulation of abscisic acid content and germinability during grain development of barley: molecular and chemical analysis of pre-harvest sprouting. J. Exp. Bot. 57, 24212434.

Chonowski, M., Corbineau, F., and Côme, D. (1997). Physiological and biochemical changes induced in sunflower seeds by osmopriming and subsequent drying, storage and aging. Seed Sci. Res. 7, 323-332.

Chun, D., Wilhelm, S., and Sagen, J. E. (1979). "Components of record germination in vitro of branched broomrape, Orobanche ramosa L.," in Supplement to the Proceedings of the Second International Symposium on Parasitic Weeds, eds L. J. Musselman, A. D. Worsham, and R. E. Eplee (Raleigh, NC: North Carolina State University), 18-22.

Clerkx, E. J. M., Blankestijn-De Vries, H., Ruys, G. J., Groot, S. P. C., and Koornneef, M. (2004). Genetic differences in seed longevity of various Arabidopsis mutants. Physiol. Plant. 121, 448-461.

Corbineau, F. (2012). Markers of seed quality: from present to future. Seed Sci. Res. 22, S61-S68.

Corbineau, F., Bagniol S., and Côme, D. (1990). Sunflower (Helianthus annuus L.) seed dormancy and its regulation by ethylene. Isr. J. Bot. 39 , 313-325.

Corbineau, F., and Côme, D. (1995) "Control of seed germination and dormancy by gaseous environment," in Seed Development and Germination, eds J. Kigel and G. Galili (New York: Marcel Dekker), 397-424.

Corbineau, F., and Côme, D. (2003). "Germination of sunflower seeds as related to ethylene synthesis and sensitivity - an overview," in Biology and Biotechnology of the Plant Hormone Ethylene, Vol. III, eds M. Vendrell, H. Klee, J. C. Pech, and F Romojaro (Amsterdam: IOS Press), 216-221.

Corbineau, F., Rudnicki, R. M., and Côme, D. (1988). Induction of secondary dormancy in sunflower seeds by high temperature. Possible involvement of ethylene biosynthesis. Physiol. Plant. 73, 368-373.

Corpas, F. J., Palma, J. M., Del Rio, L. A., and Barroso, J. B. (2009). Evidence supporting the existence of L-arginine-dependent nitric oxide synthase activity in plants. New Phytol. 184, 9-14.

Crawford, N. M. (2006). Mechanisms for nitric oxide synthesis in plants. $J$. Exp. Bot. 57, 471-478.

Cutler, S. R., Rodriguez, P. L., Finkelstein, R. R., and Abrams, S. R. (2010). Abscisic acid: emergence of a core signaling network. Annu. Rev. Plant Biol. 61, 651-679.
Dall'Osto, L., Cazzaniga, S., North, H., Marion-Poll, A., and Bassi, R. (2007). The Arabidopsis aba4-1 mutant reveals a specific function for neoxanthin in protection against photooxidative stress. Plant Cell 19, 1048-1064.

Delledonne, M. (2005). NO news is good news for plants. Curr. Opin. Plant Biol. 8, 390-396.

Dong, H., Zhen, Z., Peng, J., Chang, L., Gong, Q., and Wang, N. N. (2011). Loss of ACS7 confers abiotic stress tolerance by modulating ABA sensitivity and accumulation in Arabidopsis. J. Exp. Bot. 62, 48754887.

Dordas, C. (2009). Nonsymbiotic hemoglobins and stress tolerance in plants. Plant Sci. 176, 433-440.

Egley, G. H., and Dale, J. E. (1970). Ethylene, 2-chloroethylphosphonic acid and witchweed germination. Weed Sci. 18, 586-589.

Eick, M., and Stöhr, C. (2012). Denitrification by plant roots? New aspects of plant plasma membrane-bound nitrate reductase. Protoplasma 249, 909-918.

Endo, A., Tatematsu, K., Hanada, K., Duermeyer, L., Okamoto, M., Yonekura-Sakakibara, K., et al. (2012). Tissue-specific transcriptome analysis reveals cell wall metabolism, flavonol biosynthesis and defense responses are activated in the endosperm of germinating Arabidopsis thaliana seeds. Plant Cell Physiol. 53, 16-27.

Esashi, Y. (1991). "Ethylene and seed germination," in The Plant Hormone Ethylene, eds A. K. Mattoo and J. C. Suttle (Boca Raton, FL: CRC Press), 133-157.

Esashi, Y., and Leopold, A. C. (1969). Dormancy regulation in subterranean clover seeds by ethylene. Plant Physiol. 44, 1470-1472.

Esashi, Y., Okazaki, M., Yanai, N., and Hishinuma, K. (1978). Control of the germination of secondary dormant cocklebur seeds by various germination stimulants. Plant Cell Physiol. 19, 1497-1506.

Finch-Savage, W. E., and LeubnerMetzger, G. (2006). Seed dormancy and the control of germination. New Phytol. 171, 501-523.

Finkelstein, R., Gampala, S. S., Lynch, T. J., Thomas, T. L., and Rock, C. D. (2005). Redundant and distinct functions of the ABA response loci ABA-INSENSITIVE(ABI)5 and ABRE-BINDING FACTOR (ABF)3. Plant Mol. Biol. 59, 253-267.

Finkelstein, R. R. (1994). Mutations at two new Arabidopsis ABA response 
loci are similar to the abi3 mutations. Plant J. 5, 765-771.

Finkelstein, R. R., Reeves, W., Ariizumi, T., and Steber, C. (2008). Molecular aspects of seed dormancy. Annu. Rev. Plant Biol. 59, 387-415.

Footitt, S., Douterelo-Soler, I., Clay, H., and Finch-Savage, W. E. (2011). Dormancy cycling in Arabidopsis seeds is controlled by seasonally distinct hormone-signaling pathways. Proc. Natl. Acad. Sci. U.S.A. 108, 2023620241.

Foresi, N., Correa-Aragunde, N., Parisi, G., Calo, G., Salerno, G., and Lamattina, L. (2010). Characterization of a nitric oxide synthase from the plant kingdom: NO generation from the green alga Ostreococcus tauri is light irradiance and growth phase dependent. Plant Cell 22, 38163830.

Frey, A., Effroy, D., Lefebvre, V., Seo, M., Perreau, F., Berger, A., et al. (2012). Epoxycarotenoid cleavage by NCED5 fine-tunes ABA accumulation and regulates seed dormancy and drought tolerance with other NCED family members. Plant J. 70, 501-512.

Frey, A., Godin, B., Bonnet, M., Sotta, B., and Marion-Poll, A. (2004). Maternal synthesis of abscisic acid controls seed development and yield in Nicotiana plumbaginifolia. Planta 218, 958-964.

Fröhlich, A., and Durner, J. (2011). The hunt for plant nitric oxide synthase (NOS): is one really needed? Plant Sci. 181, 401-404.

Fu, J. R., and Yang, S. F. (1983). Release of heat pretreatment-induced dormancy in lettuce seeds by ethylene or cytokinin in relation to the production of ethylene and the synthesis of 1-aminocyclopropane1-carboxylic acid during germination. J. Plant Growth Regul. 2, 185-192.

Fujii, H., and Zhu, J. K. (2009). Arabidopsis mutant deficient in 3 abscisic acid-activated protein kinases reveals critical roles in growth, reproduction, and stress. Proc. Natl. Acad. Sci. U.S.A. 106, 8380-8385.

Gallardo, M., Del Mar Delgado, M., Sanchez-Calle, I. M., and Matilla, A. J. (1991). Ethylene production and 1-aminocyclopropane-1-carboxylic acid conjugation in thermoinhibited Cicer arietinum L. seeds. Plant Physiol. 97, 122-127.

Gallardo, M., Gallardi, M. E., Matilla, A., Munoz de Ruedo, P., and SanchezCalle, I. M. (1994). Inhibition of polyamine synthesis by cyclohexylamine stimulates the ethylene pathway and accelerates the germination of Cicer arietinum seeds. Physiol. Plant. 91, 9-16.

Gallardo, M., Sanchez-Calle, I. M. Munoz de Ruedo, P., and Matilla, A. (1996). Alleviation of thermoinhibition in chick-pea seeds by putrescine involves the ethylene pathway. Aust. J. Plant Physiol. 23, 479-487.

Gazzarrini, S., and McCourt, P. (2001). Genetic interactions between ABA, ethylene and sugar signaling pathways. Curr. Opin. Plant Biol. 4, 387-391.

Gazzarrini, S., Tsuchiya, Y., Lumba, S., Okamoto, M., and McCourt, P. (2004). The transcription factor FUSCA3 controls developmental timing in Arabidopsis through the hormones gibberellin and abscisic acid. Dev. Cell 7, 373-385.

Ghassemian, M., Nambara, E., Cutler, S., Kawaide, H., Kamiya, Y., and McCourt, P. (2000). Regulation of abscisic acid signaling by the ethylene response pathway in Arabidopsis. Plant Cell 12, 1117-1126.

Gniazdowska, A., Dobrzynska, U., Babanczyk, T., and Bogatek, R. (2007). Breaking the apple embryo dormancy by nitric oxide involves the stimulation of ethylene production. Planta 225, 1051-1057.

Gniazdowska, A., Krasuska, U., and Bogatek, R. (2010). Dormancy removal in apple embryos by nitric oxide or cyanide involves modifications in ethylene biosynthetic pathway. Planta 232, 1397-1407.

Gomez-Jimenez, M. C., Matilla, A. J., and Garrido, D. (1998). Isolation and characterization of a cDNA encoding an ACC oxidase from Cicer arietinum and its expression during embryogenesis and seed germination. Aust. J. Plant Physiol. 25, 765-773.

Gonzalez-Guzman, M., Apostolova, N., Belles, J. M., Barrero, J. M., Piqueras, P., Ponce, M. R., et al. (2002). The short-chain alcohol dehydrogenase ABA2 catalyzes the conversion of xanthoxin to abscisic aldehyde. Plant Cell 14, 1833-1846.

Gonzalez-Guzman, M., Pizzio, G. A., Antoni, R., Vera-Sirera, F., Merilo, E., Bassel, G. W., et al. (2012). Arabidopsis PYR/PYL/RCAR receptors play a major role in quantitative regulation of stomatal aperture and transcriptional response to abscisic acid. Plant Cell 24, 2483-2496.

Gorecki, R. J., Ashino, H., Satoh, S., and Esashi, Y. (1991). Ethylene production in pea and cocklebur seeds of differing vigour. J. Exp. Bot. 42, 407-414.

Graeber, K., Nakabayashi, K., Miatton, E., Leubner-Metzger, G., and Soppe,
W. J. (2012). Molecular mechanism of seed dormancy. Plant Cell Environ. 35, 1769-1786.

Gubler, F., Hughes, T., Waterhouse, P., and Jacobsen, J. (2008). Regulation of dormancy in barley by blue light and after-ripening: effects on abscisic acid and gibberellin metabolism. Plant Physiol. 147, 886-898.

Gupta, K. J., Fernie, A. R., Kaiser, W. M., and Van Dongen, J. T. (2011). On the origins of nitric oxide. Trends Plant Sci. 16, 160-168.

Gutierrez, L., Van Wuytswinkel, O., Castelain, M., and Bellini, C. (2007). Combined networks regulating seed maturation. Trends Plant Sci. 12, 294-300.

Hall, B., Shakeel, S., and Schaller, G. (2007). Ethylene receptors: ethylene perception and signal transduction. J. Plant Growth Regul. 26, 118-130.

Hanfrey, C., Sommer, S., Mayer, M. J., Burtin, D., and Michael, A. J. (2001). Arabidopsis polyamine biosynthesis: absence of ornithine decarboxylase and the mechanism of arginine decarboxylase activity. Plant J. 27, 551-560.

Hebelstrup, K. H., and Jensen, E. O. (2008). Expression of NO scavenging hemoglobin is involved in the timing of bolting in Arabidopsis thaliana. Planta 227, 917-927.

Hebelstrup, K. H., Van Zanten, M., Mandon, J., Voesenek, L. A., Harren, F. J., Cristescu, S. M., et al. (2012). Haemoglobin modulates NO emission and hyponasty under hypoxiarelated stress in Arabidopsis thaliana. J. Exp. Bot. 63, 5581-5591.

Hendricks, S. B., and Taylorson, R. B. (1974). Promotion of seed germination by nitrate, nitrite, hydroxylamine, and ammonium salts. Plant Physiol. 54, 304-309.

Hermann, K., Meinhard, J., Dobrev, P., Linkies, A., Pesek, B., Hess, B. et al. (2007). 1-aminocyclopropane1-carboxylic acid and abscisic acid during the germination of sugar beet (Beta vulgaris L.): a comparative study of fruits and seeds. J. Exp. Bot. 58, 3047-3060.

Holzmeister, C., Frohlich, A., Sarioglu, H., Bauer, N., Durner, J., and Lindermayr, C. (2011). Proteomic analysis of defense response of wildtype Arabidopsis thaliana and plants with impaired NO-homeostasis. Proteomics 11, 1664-1683.

Igamberdiev, A. U., Bykova, N. V., Shah, J. K., and Hill, R. D. (2010). Anoxic nitric oxide cycling in plants: participating reactions and possible mechanisms. Physiol. Plant. 138 393-404.
Igamberdiev, A. U., and Hill, R. D. (2004). Nitrate, NO and haemoglobin in plant adaptation to hypoxia: an alternative to classic fermentation pathways. J. Exp. Bot. 55, 2473-2482.

Iglesias-Fernandez, R., and Matilla, A. (2010). Genes involved in ethylene and gibberellins metabolism are required for endosperm-limited germination of Sisymbrium officinale L. seeds. Planta 231, 653-664.

Iuchi, S., Kobayashi, M., Taji, T., Naramoto, M., Seki, M., Kato, T., et al. (2001). Regulation of drought tolerance by gene manipulation of 9-cis-epoxycarotenoid dioxygenase, a key enzyme in abscisic acid biosynthesis in Arabidopsis. Plant J. 27, 325-333.

Jimenez, J. A., Rodriguez, D., Calvo, A. P., Mortensen, L. C., Nicolas, G., and Nicolas, C. (2005). Expression of a transcription factor (FsERF1) involved in ethylene signaling during the breaking of dormancy in Fagus sylvatica seeds. Physiol. Plant. 125, 373-380.

Johnson, R. R., Wagner, R. L., Verhey, S. D., and Walker-Simmons, M. K. (2002). The abscisic responsive PKABAl interacts with a seedspecific abscisic acid response element-binding factor TaABF, and phosphorylates TaABF peptide sequences. Plant Physiol. 130, 837-846.

Jones, J. F., and Hall, M. A. (1984). Studies on the requirement for carbon dioxide and ethylene for germination of Spergula arvensis L. seeds. Plant Sci. Lett. 16, 87-93.

Joyard, J., Ferro, M., Masselon, C., Seigneurin-Bernya, D., Salvi, D., Garin, J., etal. (2009). Chloroplast proteomics and the compartmentation of plastidial isoprenoid biosynthetic pathways. Mol. Plant 2, 1154-1180.

Kang, J., Hwang, J. U., Lee, M., Kim, Y. Y., Assmann, S. M., Martinoia, E., et al. (2010). PDR-type ABC transporter mediates cellular uptake of the phytohormone abscisic acid. Proc. Natl. Acad. Sci. U.S.A. 107, 23552360.

Kanno, Y., Hanada, A., Chiba, Y., Ichikawa, T., Nakazawa, M., Matsui, M., et al. (2012). Identification of an abscisic acid transporter by functional screening using the receptor complex as a sensor. Proc. Natl. Acad. Sci. U.S.A. 109, 9653-9658.

Kanno, Y., Jikumaru, Y., Hanada, A., Nambara, E., Abrams, S. R., Kamiya, Y., et al. (2010). Comprehensive hormone profiling in developing Arabidopsis seeds: examination 
of the site of ABA biosynthesis, ABA transport and hormone interactions. Plant Cell Physiol. 51, 19882001.

Karssen, C. M., Brinkhorst-van der Swan, D. L. C., Breekland, A. E., and Koornneef, M. (1983). Induction of dormancy during seed development by endogenous abscisic acid deficient genotypes of Arabidopsis thaliana (L.) Heynh. Planta 157, 158-165.

Katoh, H., and Esashi, Y. (1975). Dormancy and impotency of cocklebur seeds. I. $\mathrm{CO}_{2}, \mathrm{C}_{2} \mathrm{H}_{4}, \mathrm{O}_{2}$ and high temperature. Plant Cell Physiol. 16, 687-696.

Kendall, S. L., Hellwege, A., Marriot, P., Whalley, C., Graham, I. A. and Penfield, S. (2011). Induction of dormancy in Arabidopsis summer annuals requires parallel regulation of DOG1 and hormone metabolism by low temperature and CBF transcription factors. Plant Cell 23, 25682580.

Kende, H. (1993). Ethylene biosynthesis. Annu. Rev. Plant Physiol. Plant Mol. Biol. 44, 283-307.

Kende, H., van der Knaap, E., and Cho, H. T. (1998). Deepwater rice: a model plant to study stem elongation. Plant Physiol. 118, 1105-1110.

Kendrick, M. D., and Chang, C. (2008). Ethylene signaling: new levels of complexity and regulation. Curr. Opin. Plant Biol. 11, 479-485.

Kepczynski, J. (1986). Inhibition of Amaranthus caudatus seed germination by polyethylene glycol-6000 and abscisic acid and its reversal by ethephon or aminocyclopropane-1carboxylic acid. Physiol. Plant. 67, 588-591.

Kepczynski, J., Bihun, M., and Kepczynska, E. (1996a). Induction and release of secondary dormancy in Amaranthus caudatus L. seeds. Plant Physiol. Biochem. Special Issue S03-S50, 42.

Kepczynski, J., Corbineau, F., and Côme, D. (1996b). Responsiveness of Amaranthus retroflexus seeds to ethephon, 1-aminocyclopropane-1carboxylic acid and gibberellic acid in relation to temperature and dormancy. Plant Growth Regul. 20, 259-265.

Kepczynski, J., Bihun, M., and Kepczynska, E. (2003). The release of secondary dormancy by ethylene in Amaranthus caudatus L. seeds. Seed Sci. Res. 13, 69-74.

Kepczynski, J., and Karssen, C. M. (1985). Requirement for the action of endogenous ethylene during germination of non-dormant seeds of Amaranthus caudatus. Physiol. Plant. 63, 49-52.
Kepczynski, J., and Kepczynska, E. (1993). "The effect of putrescine, ethephon and ACC on germination of thermodormant Amaranthus paniculatus L. seed," in Basic and Applied Aspects of Seed Biology, Fourth International Workshop on Seeds, eds D. Côme and F. Corbineau (Paris: ASFIS), 537-554.

Kepczynski, J., and Kepczynska, E. (1997). Ethylene in seed dormancy and germination. Physiol. Plant. 101, 720-726.

Kepczynski, J., Rudnicki, R. M., and Khan, A. A. (1977). Ethylene requirement for germination of partly afterripened apple embryo. Physiol. Plant. 40, 292-295.

Ketring, D. L., and Morgan, P. W. (1969). Ethylene as a component of the emanations from germinating peanut seeds and its effect on dormant Virginia-type seeds. Plant Physiol. 44, 326-330.

Khan, A. A. (1994). ACC-derived ethylene production, a sensitive test for seed vigor. J. Am. Soc. Hortic. Sci. 119, 1083-1090.

Khan, M. A., Ansari, R., Gul, B., and Li, W. Q. (2009). Dormancy and germination responses of halophyte seeds to the application of ethylene. C. $R$. Biol. 332, 806-815.

Kobayashi, Y., Murata, M., Minami, H., Yamamoto, S., Kagaya, Y., Hobo, T., et al. (2005). Abscisic acid-activated SnRK2 protein kinases function in the gene-regulation pathway of ABA signal transduction by phosphorylating $\mathrm{ABA}$ response element-binding factors. Plant J. 44, 939-949.

Koornneef, M., Jorna, M. L., Brinkhorst-van der Swan, D. L. C., and Karssen, C. M. (1982). The isolation of abscisic acid (ABA) deficient mutants by selection of induced revertants in non-germinating gibberellin-sensitive lines of Arabidopsis thaliana (L.) Heynh. Theor. Appl. Genet. 61, 385-393.

Kucera, B., Cohn, M. A., and LeubnerMetzger, G. (2005). Plant hormone interactions during seed dormancy release and germination. Seed Sci. Res. 15, 281-307.

Kuromori, T., Miyaji, T., Yabuuchi, H., Shimizu, H., Sugimoto, E., Kamiya, A., et al. (2010). ABC transporter AtABCG25 is involved in abscisic acid transport and responses. Proc Natl. Acad. Sci. U.S.A. 107, 23612366.

Kuromori, T., Sugimoto, E., and Shinozaki, K. (2011). Arabidopsis mutants of AtABCG22, an ABC transporter gene, increase water transpiration and drought susceptibility. Plant J. 67, 885-894.
Kushiro, T., Okamoto, M., Nakabayashi, K., Yamagishi, K., Kitamura, S., Asami, T., et al. (2004). The Arabidopsis cytochrome P450 CYP707A encodes ABA 8'-hydroxylases: key enzymes in ABA catabolism. $E M B O$ J. 23, 1647-1656.

Kwon, E., Feechan, A., Yun, B. W. Hwang, B. H., Pallas, J. A., Kang, J. G., et al. (2012). AtGSNOR1 function is required for multiple developmental programs in Arabidopsis. Planta 236, 887-900.

Lee, K. H., Piao, H. L., Kim, H. Y., Choi, S. M., Jiang, F., Hartung, W. et al. (2006). Activation of glucosidase via stress-induced polymerization rapidly increases active pools of abscisic acid. Cell 126, 1109-1120.

Lee, K. P., Piskurewicz, U., Tureckova, V., Strnad, M., and Lopez-Molina L. (2010). A seed coat bedding assay shows that RGM2-dependent release of abscisic acid by the endosperm controls embryo growth in Arabidopsis dormant seeds. Proc. Natl. Acad. Sci. U.S.A. 107, 1910819113.

Lee, U., Wie, C., Fernandez, B. O., Feelisch, M., and Vierling, E. (2008) Modulation of nitrosative stress by $S$ nitrosoglutathione reductase is critical for thermotolerance and plant growth in Arabidopsis. Plant Cell 20, 786-802.

Lefebvre, V., North, H., Frey, A., Sotta, B., Seo, M., Okamoto, M., et al. (2006). Functional analysis of Arabidopsis NCED6 and NCED9 genes indicates that ABA synthesized in the endosperm is involved in the induction of seed dormancy. Plant J. 45, 309-319.

LeNoble, M. E., Spollen, W. G., and Sharp, R. E. (2004). Maintenance of shoot growth by endogenous ABA: genetic assessment of the involvement of ethylene suppression. J. Exp. Bot. 55, 237-245.

Leubner-Metzger, G., Petruzzelli, L., Waldvogel, R., Vogeli-Lange, R., and Meins, F. (1998). Ethyleneresponsive element binding protein (EREBP) expression and the transcriptional regulation of class I beta1,3-glucanase during tobacco seed germination. Plant Mol. Biol. 38, 785-795.

Leymarie, J., Benech-Arnold, R. L., Farrant, J. M., and Corbineau, F. (2009). Thermodormancy and ABA metabolism in barley grains. Plant Signal. Behav. 4, 205-207.

Lillo, C., Meyer, C., Lea, U. S., Provan, F., and Oltedal, S. (2004). Mechanism and importance of post-translational regulation of nitrate reductase. J. Exp. Bot. 55, 1275-1282.
Lim, E. K., Doucet, C. J., Hou, B., Jackson, R. G., Abrams, S. R., and Bowles, D. J. (2005). Resolution of (+)-abscisic acid using an Arabidopsis glycosyltransferase. Tetrahedron Asymmetry 16, 143-147.

Lin, Z., Zhong, S., and Grierson, D. (2009). Recent advances in ethylene research. J. Exp. Bot. 60, 3311-3336.

Lindermayr, C., Saalbach, G., Bahnweg, G., and Durner, J. (2006). Differential inhibition of Arabidopsis methionine adenosyltransferases by protein S-nitrosylation. J. Biol. Chem. 281, 4285-4291.

Lindermayr, C., Saalbach, G., and Durner, J. (2005). Proteomic identification of S-nitrosylated proteins in Arabidopsis. Plant Physiol. 137, 921-930.

Linkies, A., and Leubner-Metzger, G. (2012). Beyond gibberellins and abscisic acid: how ethylene and jasmonates control seed germination. Plant Cell Rep. 31, 253-270.

Linkies, A., Muller, K., Morris, K., Tureckova, V., Wenk, M., Cadman, C. S., et al. (2009). Ethylene interacts with abscisic acid to regulate endosperm rupture during germination: a comparative approach using Lepidium sativum and Arabidopsis thaliana. Plant Cell 21, 3803-3822.

Liu, Q., Zhou, G. Y., and Wen, C. K. (2004). Ethylene signal transduction in Arabidopsis. J. Plant Physiol. Mol. Biol. 30, 241-250.

Liu, Y., Shi, L., Ye, N., Liu, R., Jia, W., and Zhang, J. (2009). Nitric oxideinduced rapid decrease of abscisic acid concentration is required in breaking seed dormancy in Arabidopsis. New Phytol. 183, 1030-1042.

Liu, Y., Ye, N., Liu, R., Chen, M., and Zhang, J. (2010). H2O2 mediates the regulation of ABA catabolism and GA biosynthesis in Arabidopsis seed dormancy and germination. J. Exp. Bot. 61, 2979-2990.

Longan, D. C., and Stewart, G. R. (1992). Germination of the seeds of parasitic angiosperms. Seed Sci. Res. 2, 179-190.

Lopez-Molina, L., Mongrand, S., and Chua, N. H. (2001). A postgermination developmental arrest checkpoint is mediated by abscisic acid and requires the $\mathrm{ABI} 5$ transcription factor in Arabidopsis. Proc. Natl. Acad. Sci. U.S.A. 98, 4782-4787.

Lopez-Molina, L., Mongrand, S., McLachlin, D. T., Chait, B. T., and Chua, N. H. (2002). ABI5 acts downstream of $\mathrm{ABI} 3$ to execute an ABAdependent growth arrest during germination. Plant J. 32, 317-328.

Lounifi, I., Arc, E., Molasiotis, A., Job, D., Rajjou, L., and Tanou, G. (2013). 
Interplay between protein carbonylation and nitrosylation in plants. Proteomics 13, 568-578

Lozano-Juste, J., Colom-Moreno, R., and Leon, J. (2011). In vivo protein tyrosine nitration in Arabidopsis thaliana. J. Exp. Bot. 62, 3501-3517.

Lozano-Juste, J., and Leon, J. (2010). Enhanced abscisic acid-mediated responses in nialnia2noa1-2 triple mutant impaired in NIA/NR- and AtNOA1-dependent nitric oxide biosynthesis in Arabidopsis. Plant Physiol. 152, 891-903.

Ma, Y., Szostkiewicz, I., Korte, A., Moes, D., Yang, Y., Christmann, A., et al. (2009). Regulators of PP2C phosphatase activity function as abscisic acid sensors. Science 324, 1064 1068.

Machabée, S., and Saini, H. S. (1991). Differences in requirement for endogenous ethylene during germination of dormant and nondormant seeds of Chenopodium album L. J. Plant Physiol. 138, 97-101.

Mallick, N., Mohn, F. H., Rai, L. C., and Soeder, C. J. (2000). Evidence for the non-involvement of nitric oxide synthase in nitric oxide production by the green alga Scenedesmus obliquus. J. Plant Physiol. 156, 423-426.

Manjunatha, G., Gupta, K. J., Lokesh, V., Mur, L. A., and Neelwarne, B. (2012). Nitric oxide counters ethylene effects on ripening fruits. Plant Signal. Behav. 7, 476-483.

Marin, E., Nussaume, L., Quesada, A., Gonneau, M., Sotta, B., Hugueney, P., et al. (1996). Molecular identification of zeaxanthin epoxidase of Nicotiana plumbaginifolia, a gene involved in abscisic acid biosynthesis and corresponding to the ABA locus of Arabidopsis thaliana. EMBO J. 15, 23312342.

Martinez-Reina, G., Matilla, A. J., Martin-Remesal, C., Gallardo, M., and Munoz De Rueda, P. (1996). Biochemical properties of 1-aminocyclopropane-1-carboxylate $N$-malonyltransferase activity from early growing embryonic axes of chick-pea (Cicer arietinum L.) seeds. J. Exp. Bot. 47, 1771-1778.

Matakiadis, T., Alboresi, A., Jikumaru, Y., Tatematsu, K., Pichon, O., Renou, J. P., et al. (2009). The Arabidopsis abscisic acid catabolic gene CYP707A2 plays a key role in nitrate control of seed dormancy. Plant. Physiol. 149, 949-960.

Matilla, A. J. (2000). Ethylene in seed formation and germination. Seed Sci. Res. 10, 111-126.

Matilla, A. J., and Matilla-Vazquez, M. A. (2008). Involvement of ethylene in seed physiology. Plant Sci. 175, 87-97.

Mendel, R. R. (2007). Biology of the molybdenum cofactor. J. Exp. Bot. 58, 2289-2296.

Messing, S. A. J., Gabelli, S. B., Echevarria, I., Vogel, J. T., Guan J. C., Tan, B. C., et al. (2010). Structural insights into maize Viviparous14, a key enzyme in the biosynthesis of the phytohormone abscisic acid. Plant Cell 22, 2970-2980.

Millar, A. A., Jacobsen, J. V., Ross, J. J., Helliwell, C. A., Poole, A T., Scofield, G., et al. (2006). Seed dormancy and ABA metabolism in Arabidopsis and barley: the role of ABA 8'-hydroxylase. Plant J. 45, 942-954.

Miura, K., Lee, J., Jin, J. B., Yoo, C. Y., Miura, T., and Hasegawa, P. M. (2009). Sumoylation of ABI5 by the Arabidopsis SUMO E3 ligase SIZ1 negatively regulates abscisic acid signaling. Proc. Natl. Acad. Sci. U.S.A. 106, 5418-5423.

Moreau, M., Lindermayr, C., Durner, J., and Klessig, D. F. (2010). NO synthesis and signaling in plants - where do we stand? Physiol. Plant. 138, 372-383.

Mortensen, L. C., Rodriguez, D., Nicolas, G., Eriksen, E. N., and Nicolas, C. (2004). Decline in a seed-specific abscisic acid-responsive glycine rich protein (GRPF1) mRNA may reflect the release of seed dormancy in Fagus sylvatica during moist prechilling. Seed Sci. Res. 14, 27-34.

Nakabayashi, K., Bartsch, M., Xiang, Y., Miatton, E., Pellengahr, S., Yano, R., et al. (2012). The time required for dormancy release in Arabidopsis is determined by DELAY OF GERMINATION1 protein levels in freshly harvested seeds. Plant Cell 24, 2826 2838.

Nakashima, K., Fujita, Y., Kanamori, N., Katagiri, T., Umezawa, T., Kidokoro, S., et al. (2009). Three Arabidopsis SnRK2 protein kinases, SRK2D/SnRK2.2, SRK2E/SnRK2.6/OST1 and SRK2I/SnRK2.3, involved in ABA signaling are essential for the control of seed development and dormancy. Plant Cell Physiol. 50, 1345-1363.

Nambara, E., and Marion-Poll, A. (2005). ABA biosynthesis and catabolism. Annu. Rev. Plant Biol. 56, 165-185.

Nambara, E., Okamoto, M., Tatematsu, K., Yano, R., Seo, M., and Kamiya, Y. (2010). Abscisic acid and the control of seed dormancy and germination. Seed Sci. Res. 20, 55-67.

Narsai, R., Law, S. R., Carrie, C., $\mathrm{Xu}$, L., and Whelan, J. (2011). In depth temporal transcriptome profiling reveals a crucial developmental switch with roles for RNA processing and organelle metabolism that are essential for germination in Arabidopsis thaliana. Plant Physiol. 157, 1342-1362.

Negm, F. B., and Smith, O. E. (1978). Effects of ethylene and carbon dioxide on the germination of osmotically inhibited lettuce seeds. Plant Physiol. 49, 869-872.

Neill, S., Barros, R., Bright, J., Desikan, R., Hancock, J., Harrison, J., et al. (2008). Nitric oxide, stomatal closure, and abiotic stress. J. Exp. Bot. 59, 165-176.

Nonogaki, H., Bassel, G. W., and Bewley, J. D. (2010). Germination - still a mystery. Plant Sci. 179, 574-581.

North, H., Baud, S., Debeaujon, I., Dubos, C., Dubreucq, B., Grappin, P., et al. (2010). Arabidopsis seed secrets unravelled after a decade of genetic and omics-driven research. Plant $J$. 61, 971-981.

North, H., De Almeida, A., Boutin, J. P., Frey, A., To, A., Botran, L., et al. (2007). The Arabidopsis ABA-deficient mutant aba4 demonstrates that the major route for stressinduced ABA accumulation is via neoxanthin isomers. Plant J. 50, 810-824.

Okamoto, M., Kushiro, T., Jikumaru, Y., Abrams, S. R., Kamiya, Y., Seki, M., et al. (2011). ABA 9'-hydroxylation is catalyzed by CYP707A in Arabidopsis. Phytochemistry 72, 717-722.

Okamoto, M., Kuwahara, A., Seo, M., Kushiro, T., Asami, T., Hirai, N., etal. (2006). CYP707A1 and CYP707A2, which encode abscisic acid 8 -hydroxylases, are indispensable for proper control of seed dormancy and germination in Arabidopsis. Plant Physiol. 141, 97-107.

Oracz, K., El-Maarouf-Bouteau, H., Bogatek, R., Corbineau, F., and Bailly, C. (2008). Release of sunflower seed dormancy by cyanide: cross-talk with ethylene signaling pathway. J. Exp. Bot. 59, 2241-2251.

Palmieri, M. C., Lindermayr, C., Bauwe, H., Steinhauser, C., and Durner, J. (2010). Regulation of plant glycine decarboxylase by $S$-nitrosylation and glutathionylation. Plant Physiol. 152, 1514-1528.

Parani, M., Rudrabhatla, S., Myers, R. Weirich, H., Smith, B., Leaman, D. W., et al. (2004). Microarray analysis of nitric oxide responsive transcripts in Arabidopsis. Plant Biotechnol. J. 2, 359-366.

Park, B. S., Song, J. T., and Seo, H. S. (2011). Arabidopsis nitrate reductase activity is stimulated by the E3
SUMO ligase AtSIZ1. Nat. Commun. 2, 400.

Park, S. Y., Fung, P., Nishimura, N., Jensen D. R., Fujii, H., Zhao, Y., et al. (2009). Abscisic acid inhibits type $2 \mathrm{C}$ protein phosphatases via the PYR/PYL family of START proteins. Science 324, 1068-1071.

Penfield, S., Li, Y., Gilday, A. D., Graham, S., and Graham, I. A. (2006). Arabidopsis ABA INSENSITIVE4 regulates lipid mobilization in the embryo and reveals repression of seed germination by the endosperm. Plant Cell 18, 1887-1899.

Perazzolli, M., Dominici, P., RomeroPuertas, M. C., Zago, E., Zeier, J., Sonoda, M., et al. (2004). Arabidopsis nonsymbiotic hemoglobin AHb1 modulates nitric oxide bioactivity. Plant Cell 16, 2785-2794.

Petruzzelli, L., Coraggio, I., and Leubner-Metzger, G. (2000). Ethylene promotes ethylene biosynthesis during pea seed germination by positive feedback regulation of 1 aminocyclo-propane-1-carboxylic acid oxidase. Planta 211, 144-149.

Petruzzelli, L., Sturaro, M., Mainieri, D., and Leubner-Metzger, G. (2003). Calcium requirement for ethylenedependent responses involving 1-aminocyclopropane-1-carboxylic acid oxidase in radicle tissues of germinated pea seeds. Plant Cell Environ. 26, 661-671.

Pirrello, J., Jaimes-Miranda, F., SanchezBallesta, M. T., Tournier, B., KhalilAhmad, Q., Regad, F., et al. (2006). Sl-ERF2, a tomato ethylene response factor involved in ethylene response and seed germination. Plant Cell Physiol. 47, 1195-1205.

Piskurewicz, U., Jikumaru, Y., Kinoshita, N., Nambara, E., Kamiya, Y., and Lopez-Molina, L. (2008). The gibberellic acid signaling repressor RGL2 inhibits Arabidopsis seed germination by stimulating abscisic acid synthesis and ABI5 activity. Plant Cell 20, 2729-2745.

Piskurewicz, U., Tureckova, V., Lacombe, E., and Lopez-Molina, L. (2009). Far-red light inhibits germination through DELLAdependent stimulation of ABA synthesis and $\mathrm{ABI} 3$ activity. EMBO J. 28, 2259-2271.

Piterkova, J., Luhova, L., Hofman, J., Tureckova, V., Novak, O., Petrivalsky, M., et al. (2012). Nitric oxide is involved in light-specific responses of tomato during germination under normal and osmotic stress conditions. Ann. Bot. 110, 767-776.

Planchet, E., Jagadis Gupta, K., Sonoda, M., and Kaiser, W. M. (2005). Nitric oxide emission from tobacco 
leaves and cell suspensions: rate limiting factors and evidence for the involvement of mitochondrial electron transport. Plant J. 41, 732-743.

Priest, D. M., Ambrose, S. J., Vaistij, F. E., Elias, L., Higgins, G. S., Ross, A. R., et al. (2006). Use of the glucosyltransferase UGT71B6 to disturb abscisic acid homeostasis in Arabidopsis thaliana. Plant J. 46, 492-502.

Prusinski, J., and Khan, A. A. (1990). Relationship of ethylene production to stress alleviation in seeds of lettuce cultivars. J. Am. Soc. Hortic. Sci. 115, 294-298.

Puga-Hermida, M. I., Gallardo, M. Rodroguez-Gacio, M. D., and Matilla, A. J. (2003). The heterogeneity of turnip-tops (Brassica rapa) seeds inside the silique affects germination, the activity of the final step of the ethylene pathway, and abscisic acid and polyamine content. Funct. Plant Biol. 30, 767-775.

Qiao, H., Chang, K. N., Yazaki, J., and Ecker, J. R. (2009). Interplay between ethylene, ETP1/ETP2 F-box proteins, and degradation of EIN2 triggers ethylene responses in Arabidopsis. Genes Dev. 23, 512-521.

Rajjou, L., Duval, M., Gallardo, K., Catusse, J., Bally, J., Job, C., et al. (2012). Seed germination and vigor. Annu. Rev. Plant Biol. 63, 507-533.

Rasul, S., Dubreuil-Maurizi, C., Lamotte, O., Koen, E., Poinssot, B., Alcaraz, G., et al. (2012). Nitric oxide production mediates oligogalacturonide-triggered immunity and resistance to Botrytis cinerea in Arabidopsis thaliana. Plant Cell Environ. 35, 1483-1499.

Ribeiro, D. M., and Barros, R. S. (2006). Sensitivity to ethylene as a major component in the germination of seeds of Stylosanthes humilis. Seed Sci. Res. 16, 37-45.

Roberts, E. H., and Smith, R. D. (1977). "Dormancy and the pentose phosphate pathway," in The Physiology and Biochemistry of Seed Dormancy and Germination, ed. A. A. Khan (Amsterdam: Elsevier), 385-411.

Rockel, P., Strube, F., Rockel, A., Wildt, J., and Kaiser, W. M. (2002). Regulation of nitric oxide $(\mathrm{NO})$ production by plant nitrate reductase in vivo and in vitro. J. Exp. Bot. 53, 103-110.

Rodriguez-Gacio, M. C., Nicolas, C., and Matilla, A. J. (2004). The final step of the ethylene biosynthesis pathway in turnip tops (Brassica rapa): molecular characterization of the 1-aminocyclopropane1-carboxylate oxidase BrACO1 throughout zygotic embryogenesis and germination of heterogeneous seeds. Physiol. Plant. 121, 132-140.

Romero-Puertas, M. C., Campostrini, N., Matte, A., Righetti, P. G., Perazzolli, M., Zolla, L., et al. (2008). Proteomic analysis of $S$-nitrosylated proteins in Arabidopsis thaliana undergoing hypersensitive response. Proteomics 8, 1459-1469.

Rook, F., Corke, F., Card, R., Munz, G., Smith, C., and Bevan, M. W. (2001) Impaired sucrose-induction mutants reveal the modulation of sugarinduced starch biosynthetic gene expression by abscisic acid signalling. Plant J. 26, 421-433.

Rosales, E. P., Iannone, M. F., Groppa, M. D., and Benavides, M. P. (2011). Nitric oxide inhibits nitrate reductase activity in wheat leaves. Plant Physiol. Biochem. 49, 124-130.

Rubio, S., Rodrigues, A., Saez, A., Dizon, M. B., Galle, A., Kim, T. H., et al. (2009). Triple loss of function of protein phosphatases type $2 \mathrm{C}$ leads to partial constitutive response to endogenous abscisic acid. Plant Physiol. 150, 1345-1355.

Ruiz-Sola, M. A., and RodríguezConcepción, M. (2012). Carotenoid biosynthesis in Arabidopsis: a colorful pathway. Arabidopsis Book 10:e158. doi: 10.1199/tab.0158

Rümer, S., Gupta, K. J., and Kaiser, W. M. (2009). Plant cells oxidize hydroxylamines to NO. J. Exp. Bot. 60, 2065-2072.

Rzewuski, G., and Sauter, M. (2008). Ethylene biosynthesis and signaling in rice. Plant Sci. 175, 32-42.

Saito, S., Hirai, N., Matsumoto C., Ohigashi, H., Ohta, D., Sakata, K., et al. (2004). Arabidopsis CYP707As encode $(+)$-abscisic acid 8 -hydroxylase, a key enzyme in the oxidative catabolism of abscisic acid. Plant Physiol. 134, 1439-1449.

Sakamoto, A., Ueda, M., and Morikawa, H. (2002). Arabidopsis glutathionedependent formaldehyde dehydrogenase is an $S$-nitrosoglutathione reductase. FEBS Lett. 515, 20-24.

Samimy, C., and Khan, A. A. (1983). Secondary dormancy, growthregulator effects, and embryo growth potential in curly dock (Rumex crispus) seeds. Weed Sci. 31, 153-158. Samimy, C., and Taylor, A. G. (1983). Influence of seed quality on ethylene production of germinating snap bean seeds. J. Am. Soc. Hortic. Sci. 108 767-769.

Santos-Mendoza, M., Dubreucq, B., Baud, S., Parcy, F., Caboche M., and Lepiniec, L. (2008). Deciphering gene regulatory networks that control seed development and maturation in Arabidopsis. Plant J. 54, 608-620.
Saran, M., Michel, C., and Bors, W. (1990). Reaction of NO with $\mathrm{O}^{2-}$. Implications for the action of endothelium-derived relaxing factor (EDRF). Free Radic. Res. Commun. 10, 221-226.

Satoh, S., Takeda, Y., and Esashi, Y. (1984). Dormancy and impotency of cocklebur seeds. IX. Changes in ACC-ethylene conversion activity and ACC content of dormant and non-dormant seeds during soaking. J. Exp. Bot. 35, 1515-1524.

Schönbeck, M. W., and Egley, G. H. (1981). Phase-sequence of redroot pigweed seed germination responses to ethylene and other stimuli. Plant Physiol. 68, 175-179.

Schwartz, S. H., Tan, B. C., Gage, D. A., Zeevaart, J. A., and McCarty, D. R. (1997). Specific oxidative cleavage of carotenoids by VP14 of maize. Science 276, 1872-1874.

Sen, S. (2010). S-nitrosylation process acts as a regulatory switch for seed germination in wheat. Am. J. Plant Physiol. 5, 122-132.

Seo, M., Hanada, A., Kuwahara, A., Endo, A., Okamoto, M., Yamauchi, Y., et al. (2006). Regulation of hormone metabolism in Arabidopsis seeds: phytochrome regulation of abscisic acid metabolism and abscisic acid regulation of gibberellin metabolism. Plant J. 48, 354-366.

Seo, M., Nambara, E., Choi, G., and Yamaguchi, S. (2009). Interaction of light and hormone signals in germinating seeds. Plant Mol. Biol. 69, 463-472.

Seo, M., Peeters, A. J., Koiwai, H., Oritani, T., Marion-Poll, A., Zeevaart, J. A., et al. (2000). The Arabidopsis aldehyde oxidase 3 (AAO3) gene product catalyzes the final step in abscisic acid biosynthesis in leaves. Proc Natl. Acad. Sci. U.S.A. 97, 1290812913.

Sharp, R. E., LeNoble, M. E., Else, M. A., Thorne, E. T., and Gherardi, F. (2000). Endogenous ABA maintains shoot growth in tomato independently of effects on plant water balance: evidence for an interaction with ethylene. J. Exp. Bot. 51, 1575 1584.

Simontacchi, M., Jasid, S., and Puntarulo, S. (2007). "Enzymatic sources of nitric oxide during seed germination," in Nitric Oxide in Plant Growth, Development and Stress Physiology, eds. L. Lamattina and J. Polacco (Berlin: Springer), 73-90.

Sinska, I. (1989). Interaction of ethephon with cytokinin and gibberellin during the removal of apple seed dormancy and germination of embryos. Plant Sci. 64, 39-44.
Sinska, I., and Gladon, R. (1984). Ethylene and the removal of embryonal apple seed dormancy. HortScience 19, 73-75.

Sinska, I., and Gladon, R. (1989). Effects of inhibitors of synthesis and action of ethylene on apple seed stratification and embryo germination. Acta Physiol. Plant. 11, 307-316.

Sinska, I., and Lewandowska, U. (1991). Polyamines and ethylene in the removal of embryonal dormancy in apple seeds. Physiol. Plant. 81, 59-64.

Siriwitayawan, G., Geneve, R. L., and Downie, A. B. (2003). Seed germination of ethylene perception mutants of tomato and Arabidopsis. Seed Sci. Res. 13, 303-314.

Sirova, J., Sedlarova, M., Piterkova, J., Luhova, L., and Petrivalsky, M. (2011). The role of nitric oxide in the germination of plant seeds and pollen. Plant Sci. 181, 560-572.

Smith, J. M., and Arteca, R. N. (2000). Molecular control of ethylene production by cyanide in Arabidopsis thaliana. Physiol. Plant. 109, 180-187.

Soon, F. F., Ng, L. M., Zhou, X. E., West, G. M., Kovach, A., Tan, M. H., et al. (2012). Molecular mimicry regulates ABA signaling by SnRK2 kinases and PP2C phosphatases. Science 335, 85-88.

Speer, H. L., Hsiao, A. I., and Vidaver, W. (1974). Effects of germination promoting substances given in conjunction with red light on the phytochrome-mediated germination of dormant lettuce seeds ( $\mathrm{Lac}$ tuca sativa L.). Plant Physiol. 54, 852-854.

Stamler, J. S., Singel, D. J., and Loscalzo, J. (1992). Biochemistry of nitric oxide and its redox-activated forms. Science 258, 1898-1902.

Stepanova, A. N., and Alonso, J. M. (2009). Ethylene signaling and response: where different regulatory modules meet. Curr. Opin. Plant Biol. 12, 548-555.

Stöhr, C., and Stremlau, S. (2006). Formation and possible roles of nitric oxide in plant roots. J. Exp. Bot. 57, 463-470.

Stöhr, C., Strube, F., Marx, G., Ullrich, W. R., and Rockel, P. (2001). A plasma membrane-bound enzyme of tobacco roots catalyses the formation of nitric oxide from nitrite. Planta $212,835-841$.

Subbiah, V., and Reddy, K. J. (2010). Interactions between ethylene, abscisic acid and cytokinin during germination and seedling establishment in Arabidopsis. J. Biosci. 35, 451-458. 
Sugimoto, K., Takeuchi, Y., Ebana, K., Miyao, A., Hirochika, H., Hara, N., et al. (2010). Molecular cloning of Sdr4, a regulator involved in seed dormancy and domestication of rice. Proc. Natl. Acad. Sci. U.S.A. 107, 5792-5797.

Tan, B. C., Joseph, L. M., Deng, W. T., Liu, L., Li, Q. B., Cline, K., et al. (2003). Molecular characterization of the Arabidopsis 9-cis epoxycarotenoid dioxygenase gene family. Plant J. 35 , 44-56.

Tan, B. C., Schwartz, S. H., Zeevaart, J. A., and McCarty, D. R. (1997). Genetic control of abscisic acid biosynthesis in maize. Proc. Natl. Acad. Sci. U.S.A. 94, 12235 12240.

Tanou, G., Job, C., Rajjou, L., Arc, E., Belghazi, M., Diamantidis, G., et al. (2009). Proteomics reveals the overlapping roles of hydrogen peroxide and nitric oxide in the acclimation of citrus plants to salinity. Plant J. 60, 795-804.

Taylorson, R. B. (1979). Response of weed seeds to ethylene and related hydrocarbons. Weed Sci. 27, 7-10.

Teng, S., Rognoni, S., Bentsink, L., and Smeekens, S. (2008). The Arabidopsis GSQ5/DOG1 Cvi allele is induced by the ABA-mediated sugar signalling pathway, and enhances sugar sensitivity by stimulating ABI4 expression. Plant J. 55, 372-381.

Thiel, J., Rolletschek, H., Friedel, S., Lunn, J. E., Nguyen, T. H., Feil, R., etal. (2011). Seed-specific elevation of non-symbiotic hemoglobin AtHbl: beneficial effects and underlying molecular networks in Arabidopsis thaliana. BMC Plant Biol. 11:48. doi: 10.1186/1471-2229-11-48

Toh, S., Imamura, A., Watanabe, A., Nakabayashi, K., Okamoto, M., Jikumaru, Y., et al. (2008). High temperature-induced abscisic acid biosynthesis and its role in the inhibition of gibberellin action in Arabidopsis seeds. Plant Physiol. 146, 1368-1385.

Tun, N. N., Santa-Catarina, C., Begum, T., Silveira, V., Handro, W., Floh, E. I., et al. (2006). Polyamines induce rapid biosynthesis of nitric oxide (NO) in Arabidopsis thaliana seedlings. Plant Cell Physiol. 47, 346-354.

Umezawa, T., Sugiyama, N., Mizoguchi, M., Hayashi, S., Myouga, F., Yamaguchi-Shinozaki, K., et al. (2009). Type 2C protein phosphatases directly regulate abscisic acid-activated protein kinases in Arabidopsis. Proc. Natl. Acad. Sci. U.S.A. 106, 17588-17593.

Vahala, J., Schlagnhaufer, C. D., and Pell, E. J. (1998). Induction of an ACC synthase cDNA by ozone in light-grown Arabidopsis thaliana leaves. Physiol. Plant. 103, 45-50.

Wang, K. L. C., Li, H., and Ecker, J. R. (2002). Ethylene biosynthesis and signaling networks. Plant Cell 14(Suppl.), S131-S151.

Wang, N. N., Shih M. C., and Li, N. (2005). The GUS reporteraided analysis of the promoter activities of Arabidopsis ACC synthase genes AtACS4, AtACS5, and AtACS7 induced by hormones and stresses. J. Exp. Bot. 56, 909-920.

Wang, P., Du, Y., Li, Y., Ren, D., and Song, C. P. (2010). Hydrogen peroxide-mediated activation of MAP kinase 6 modulates nitric oxide biosynthesis and signal transduction in Arabidopsis. Plant Cell 22, 29812998.

Wang, P., Du, Y., and Song, C. P. (2011). Phosphorylation by MPK6: a conserved transcriptional modification mediates nitrate reductase activation and NO production? Plant Signal. Behav. 6, 889-891.

Wang, Y., Liu, C., Li, K., Sun, F., Hu, H., Li, X., et al. (2007). Arabidopsis EIN2 modulates stress response through abscisic acid response pathway. Plant Mol. Biol. 64, 633-644.

Weitbrecht, K., Müller, K., and LeubnerMetzger, G. (2011). First of the mark: early seed germination. J. Exp. Bot. $62,3289-3309$

Wilkinson, J. Q., and Crawford, N. M. (1991). Identification of the Arabidopsis CHL3 gene as the nitrate reductase structural gene NIA2. Plant Cell 3, 461-471.

Wilkinson, J. Q., and Crawford, N. M. (1993). Identification and characterization of a chlorate-resistant mutant of Arabidopsis thaliana with mutations in both nitrate reductase structural genes NIA1 and NIA2. Mol. Gen. Genet. 239 , 289-297.

Wimalasekera, R., Tebartz, F., and Scherer, G. F. (2011a). Polyamines, polyamine oxidases and nitric oxide in development, abiotic and biotic stresses. Plant Sci. 181, 593-603.

Wimalasekera, R., Villar, C., Begum, T., and Scherer, G. F. (2011b). COPPER AMINE OXIDASE1 (CuAO1) of Arabidopsis thaliana contributes to abscisic acid- and polyamineinduced nitric oxide biosynthesis and abscisic acid signal transduction. Mol. Plant 4, 663-678.

Wollers, S., Heidenreich, T., Zarepour, M., Zachmann, D., Kraft, C., Zhao, Y., et al. (2008). Binding of sulfurated molybdenum cofactor to the C-terminal domain of ABA3 from Arabidopsis thaliana provides insight into the mechanism of molybdenum cofactor sulfuration. J. Biol. Chem. 283, 9642-9650.

Xi, W., Liu, C., Hou, X., and Yu, H. (2010). MOTHER OF FT AND TFL1 regulates seed germination through a negative feedback loop modulating ABA signaling in Arabidopsis. Plant Cell 22, 1733-1748.

Xiong, L., Ishitani, M., Lee, H., and Zhu, J. K. (2001). The Arabidopsis LOS5/ABA3 locus encodes a molybdenum cofactor sulfurase and modulates cold stress- and osmotic stressresponsive gene expression. Plant Cell 13, 2063-2083.

Xiong, L., Lee, H., Ishitani, M., and Zhu, J. K. (2002). Regulation of osmotic stress-responsive gene expression by the LOS6/ABA1 locus in Arabidopsis. J. Biol. Chem. 277, 8588-8596.

Xu, Z. Y., Lee, K. H., Dong, T., Jeong, J. C., Jin, J. B., Kanno, Y., et al. (2012). A vacuolar beta-glucosidase homolog that possesses glucoseconjugated abscisic acid hydrolyzing activity plays an important role in osmotic stress responses in Arabidopsis. Plant Cell 24, 2184 2199.

Yamagami, T., Tsuchisaka, A., Yamada K., Haddon, W. F., Harden, L. A., and Theologis, A. (2003). Biochemical diversity among the 1-aminocyclopropane-1-carboxylate synthase isozymes encoded by the Arabidopsis gene family. J. Biol. Chem. 278, 49102-49112.

Yamasaki, H., Sakihama, Y., and Takahashi, S. (1999). An alternative pathway for nitric oxide production in plants: new features of an old enzyme. Trends Plant Sci. 4, 128-129.

Yang, S. F., and Hoffman, N. E. (1984). Ethylene biosynthesis and its regulation in higher plants. Annu. Rev. Plant Physiol. Plant Mol. Biol. 35, 155-189. Yoo, S. D., Cho, Y. H., Tena, G., Xiong, Y., and Sheen, J. (2008). Dual control of nuclear EIN3 by bifurcate MAPK cascades in $\mathrm{C} 2 \mathrm{H} 4$ signalling. Nature 451, 789-795.

Zhang, Y., Liu, Z., Liu, R., Wang, L., and Bi, Y. (2011). Gibberellins negatively regulate light-induced nitrate reductase activity in Arabidopsis seedlings. J. Plant Physiol. 168, 2161-2168.

Zhou, R., Cutler, A. J., Ambrose, S. J., Galka, M. M., Nelson, K. M., Squires, T. M., et al. (2004). A new abscisic acid catabolic pathway. Plant Physiol. 134, 361-369.

Conflict of Interest Statement: The authors declare that the research was conducted in the absence of any commercial or financial relationships that could be construed as a potential conflict of interest.

Received: 08 January 2013; accepted: 05 March 2013; published online: 26 March 2013.

Citation: Arc E, Sechet J, Corbineau F, Rajjou L and Marion-Poll A (2013) ABA crosstalk with ethylene and nitric oxide in seed dormancy and germination. Front. Plant Sci. 4:63. doi: 10.3389/ fpls.2013.00063

This article was submitted to Frontiers in Plant Cell Biology, a specialty of Frontiers in Plant Science.

Copyright (C) 2013 Arc, Sechet, Corbineau, Rajjou and Marion-Poll. This is an openaccess article distributed under the terms of the Creative Commons Attribution License, which permits use, distribution and reproduction in other forums, provided the original authors and source are credited and subject to any copyright notices concerning any third-party graphics etc. 